Portland State University

PDXScholar

$1-1-1982$

\title{
The Relationship of Role Organization and Role Deprivation to Nurses' Views toward the Requirement for Entry into Professional Practice and its Related Issues
}

Paula G. Morton

Portland State University

Follow this and additional works at: https://pdxscholar.library.pdx.edu/open_access_etds

Part of the Education Commons, and the Nursing Commons Let us know how access to this document benefits you.

\section{Recommended Citation}

Morton, Paula G., "The Relationship of Role Organization and Role Deprivation to Nurses' Views toward the Requirement for Entry into Professional Practice and its Related Issues" (1982). Dissertations and Theses. Paper 802.

https://doi.org/10.15760/etd.802

This Dissertation is brought to you for free and open access. It has been accepted for inclusion in Dissertations and Theses by an authorized administrator of PDXScholar. Please contact us if we can make this document more accessible: pdxscholar@pdx.edu. 


\section{THE RELATIONSHIP OF ROLE ORGANIZATION \\ AND ROLE DEPRIVATION TO NURSES' VIEAS TOWARD \\ THE REQUIREMENT FOR ENTRY INTO PROFESSIONAL PRACTICE \\ AND ITS RELATED ISSUES}

by

Paula G. Morton

A dissertation submitted in partial fulfillment of the requirements for the degree of

DOCTOR OF EDUCATION



(C) 1982 Paula G. Morton 
AN ABSTRACT OF OF THE DISSERTATION OF Paula G. Morton for the Doctor of Education presented November 3, 1982.

Title: The Relationship of Role Organization and Role Deprivation to Nurses' Views Toward the Requirement for Entry into Professional Practice and Its Related Issues.

APPROVED BY MEMBERS OF THE DISSERTATION COMMITTEE:

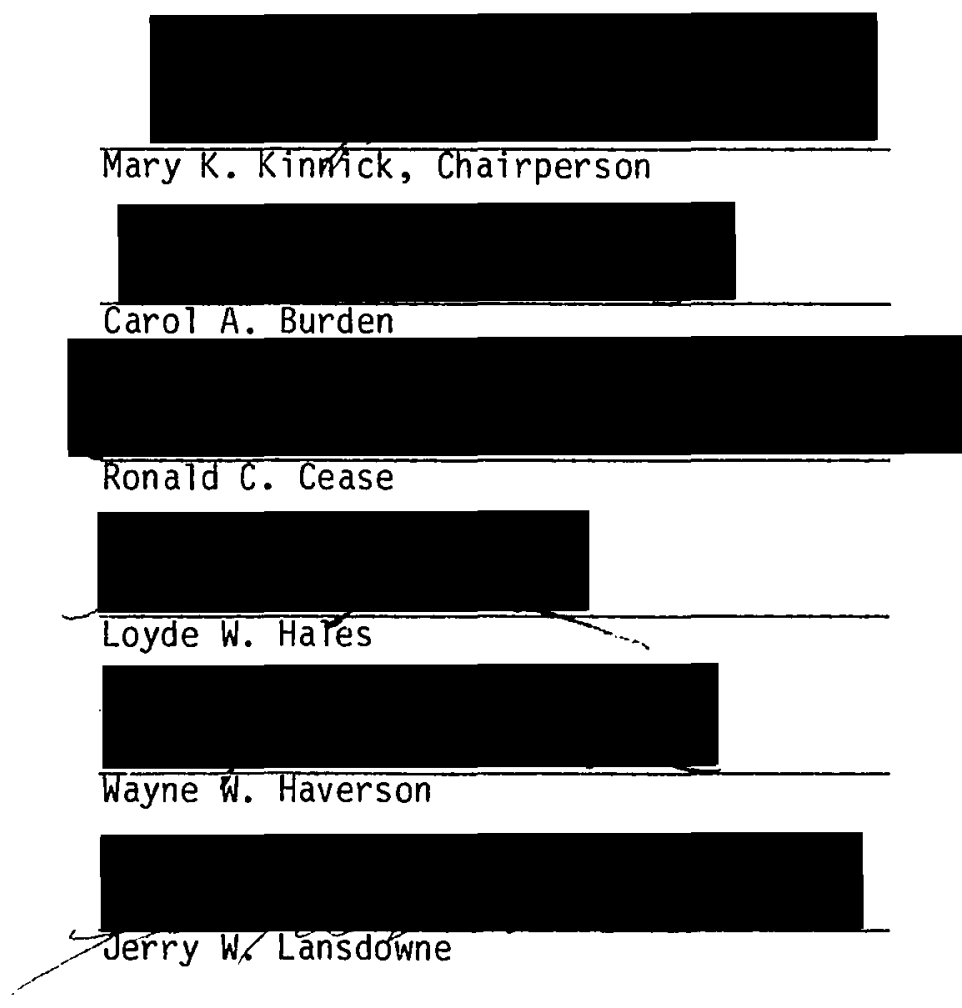

A national resolution to alter the educational and practice requirements for nurses by 1985 has been adopted in Oregon. It has been theorized that how nurses organize their multiple roles and the degrees of role deprivation they experience will affect their views 
toward professional issues. Prior research suggests there may be a relationship between certain demographic variables and nurses' role organization and role deprivation.

The study sought to establish the relationship of selected demographic variables and the variables of type of role organization and deprivation to nurses' views of four facets of the 1985 Resolution. The intent was to examine the efficacy of a conceptual model of role organization and deprivation in distinguishing and explaining nurses' views toward the resolution. As a further research contribution to nurse role theory development, the effects of nursing education preparation and length of work experience on the variables of role organization type and role deprivation were examined.

The data were obtained by mailed questionnaire using 247 nurses randomly selected in Oregon. Instrumentation included a demographics sheet, a role organization tool, and a questionnaire on the resolution. The data were analyzed using Chi-square crosstabulations and Factorial ANOVA.

Oregon nurses were found to be equally divided in their views on two levels of nursing practice and a bachelor's requirement for entry into professional practice. The majority supported inclusion of a protective clause in the resolution for currently licensed nurses and development of a nurse career ladder.

The relationship of selected demographic variables to nurses' views on the resolution were examined and established. Significant differences were found among nurses when type of basic nursing education program and level of nursing education achieved were considered. 
Baccalaureate nurses more frequentiy supported two levels of practice and a bachelor's requirement than did either associate degree or diploma nurses. They were found to differ significantiy from associate degree and diploma nurses in their degree of opposition to a protective clause in the resolution.

Significant differences in views on all resolution items were found when advanced nursing education preparation was considered. As the level of nursing preparation beyond the basic program increased, the degree of support for the two levels of practice and bachelor's requirement increased and the greater the opposition expressed to both the protective clause and the career ladder.

Subjects differed significantly in their views when type of role organization and role deprivation were examined. Nurses with high bureaucratic-high professional allegiances and nurses with low bureaucratic-high professional allegiances were more supportive of the resolution than were nurses with either high bureaucratic-low professiena? allegiances or low bureaucratic-low professional allegiances. Hurses with a high degree of role deprivation were significantly more supportive of the resolution than were nurses with low role deprivation.

The main and interaction effects of type of nursing preparation and length of work experience on the degrees of professional allegiance, bureaucratic allegiance, and role deprivation revealed that bureaucratic allegiance increases with work experience. No effect of the two variables on degree of role deprivation was found. Type of nursing program and length of work experience were found to inceract and significantly affect the degree of professional allegiance. As length of work experience 
increased for associate degree and baccalaureate nurses, professional allegiance declined. Allegiance to professional ideals was found to increase with length of work experience for diploma nurses.

The relationship of demographic and role organization variables to nurses' views on selected issues was established in the study. Role organization type, role deprivation, type of nursing preparation, and extent of nursing education are associated with nurses' views toward the resolution. 
TO THE OFFICE OF GRADUATE STUDIES AND RESEARCH:

The members of the committee approve the dissertation of Paula G. Morton, presented November 3, 1982.
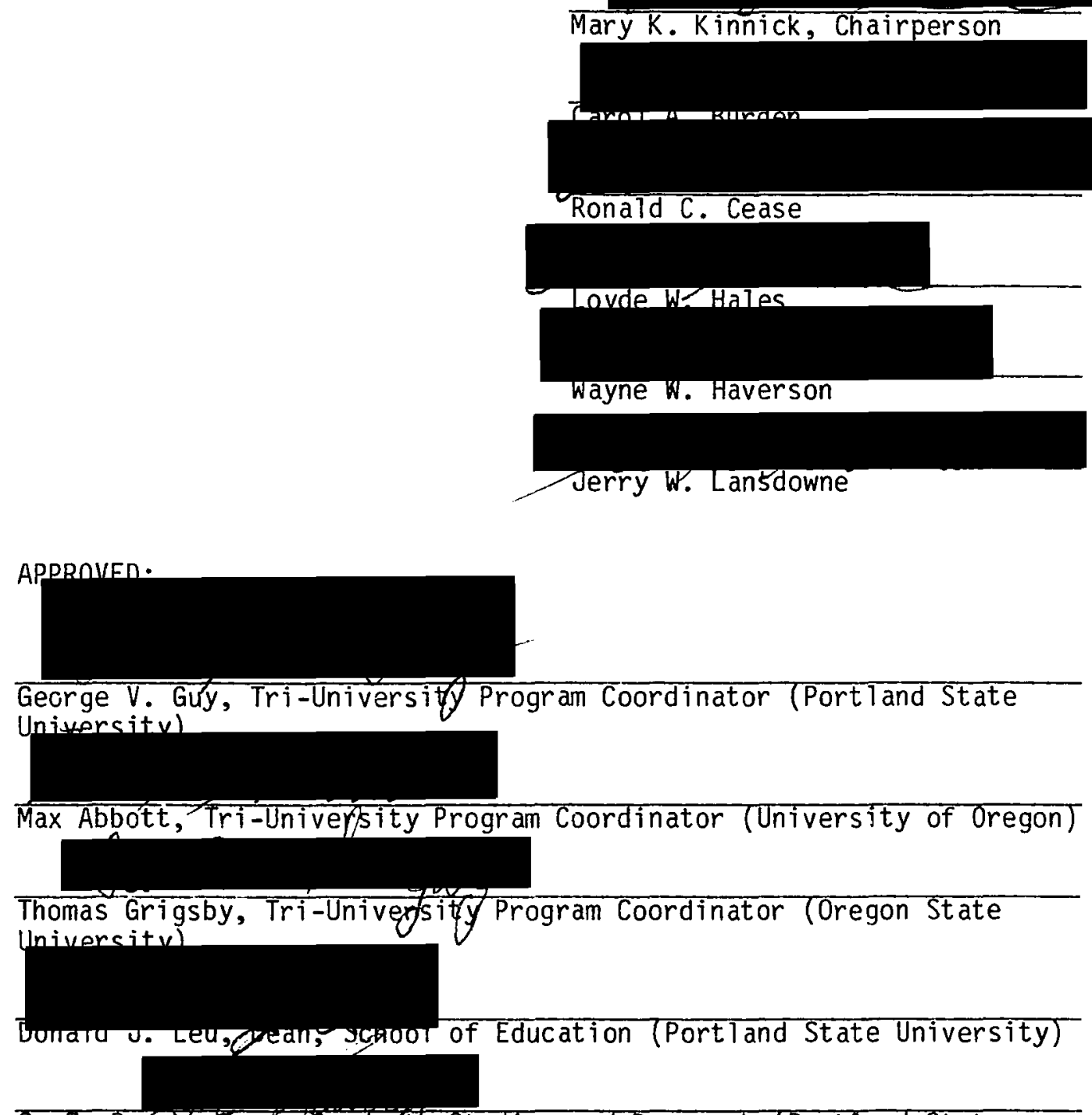

S. E. Rauch, Dean, Graduate Studies and Research (Portland State University) 
Dedicated to

the memory of Victor L. Morton 


\section{ACKNOWLEDGEMENTS}

Acknowiedgement is aue to the members of the Educational Departments of the Tri-University Program who stimulated and guided my interest in the study. I am grateful to Professors Burden, Hales, Haverson, and Lansdowne for their challenging ideas, scholarly interest, and invaluable assistance in the development and completion of the research project.

Particular appreciation is expressed to Mary Kinnick, Ph.D., whose intellectual curiosity and design expertise have substantially contributed to this work. I am indebted to her as a source of many ideas expressed in this study.

Appreciation is expressed to Larry Burden for his assistance in organizing the data and clarifying the content of the manuscript and to Mary Ann and Virgil Conley and Zella Morton for their assistance in mailing questionnaires.

The assistance of the following two individuals is greatly appreciated: Garnet Oekerman, Assistant Executive Director of the Dregon state Board of Nursing, for her invaluable help in identifying the subjects of the study; and Janet Teaff, Assistant Executive Director of the Oregon Nurses' Association, for providing current literature. Acknowledgement is given to Ronald Corwin, Ph.D., 
Anthony Lee, Editor of RN Magazine; and to RN Magazine for their permission to adapt and utilize the research instruments.

Appreciation is expressed to Marie Beaudet-Walters for her guidance in the computer analyses and interpretation of the data.

For her continuous encouragement, gratitude is expressed to Beatrice Duffy, R.N., M.A., the individual who has most significantly infuenced my understanding and appreciation of the historical and current issues affecting professional education and practice in nursing.

I wish to express my deepest appreciation to my famiIy, Zella and Victor L. Morion and Victor G. and Younga Morton, for their support and patience over the years. I am particularly grateful to my father, Victor L., whose sustaining vision and encouragement led to the completion of this work.

Paula G. Morton 
ACKNOWLEDGEMENTS .................. . . . iv

LIST OF TABLES . . . . . . . . . . . . . . . . ix

LIST OF FIGURES . . . . . . . . . . . . . . . xiii

CHAPTER

I INTRODUCTION . . . . . . . . . . . . . I 1

Introduction to the Problem .......... I

The Background of the Study

A Conceptual Framework

Statement of the Problen ........... 7

The Research Questions ... . . . . . 8

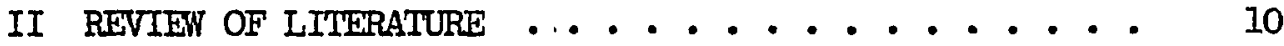

Historical Background ............ 10

Two Levels of Nursing

Niursing Roile Organization . . . . . . . . 15

Service Role Conception

Bureaucratic Role Conception

Professional Role Conception

The Organization of Nursing Roles

Role Deprivation

The 1985 Resolution . . . . . . . . . .

Professional/Technical Differentiation

Entry Requirement for Professional Practice

The Grandfather Clause

The Ladder Mechanism 
Conclusion ..............

CHAPTIR

III VELTODOLOCYY . . . . . . . . . . . 40

Design .................. 40

Subjects.............. . . . . 40

Instrumentation ............. . . . 41

Demographic Dat3 Sheet

Role Organization Instrument

Views Toward the 1985 Resolution Instrument

Procedures . . . . . . . . . . . 50

Statistical Methods . . . . . . . . . 52

Chi-Square

Factorial Analysis of Variance

Additional Analysis

IV ANALYSIS AND DISCUSSICRT . . . . . . . . .

Demographic Characteristics ......... 39

Views Toward tine 1985 Resolution ....... E4

Nurses' Views

Relationship cI Denographic Variables

Relationship of Role Organization

Relationship of Role Deprivation

Interactions of Factors affecting

Role Organization

Interactions of Factors Affecting

Role Deprivation

V STMMARY, CONCLUSICNS, AND RECOMRERDATICNS . . . IC4

Surmary ............... . . . IC4

Conclusions . . . . . . . . . . 109

Recomendations ........... 118 
viii

PAGE

REFERENCES . . . . . . . . . . . . . . . .

126

REFERENCE NOTES ....................

135

APPENDICES . . . . . . . . . . . . . . . .

136

APPENDIX A, INVITATIONAL AND FOLIOW UP IETTERS . . .

137

APPENDIX B, INSTRLMENTATION . . . . . . . . 


\section{LIST OF TABLES}

I The Number and Per Cent of Completed Questionnaires

Returned in Response to Each of Three Mailings . .

II Demographic Variables of the Sample Reported in Frequencies and Percentage of Subjects . . . . . 60

III Sumary of Subjects' Responses to Four Items of the 1985 Resolution ..............

IV Results of Multiple Chi-Square Tests on Responses to the Four Facets of the Resolution by Categories of Demographic Variables . . . . . . . . .

V Subjects' Responses by Type of Basic Nursing Education to the Statement, "Nursing Should be Divided into Registered Professional and Registered Technical Nurses..." . . . . . . .

VI Subjects' Responses by Type of Basic Nursing Education Preparation to the Statement, "...The Bachelor's Degree should be Required for........Professional Nurse..." . . . . . . . . . . .

VII Subjects' Responses by Type of Basic Nursing Education Preparation to the Statement, "Legislation Implementing the Proposal Should Not Include a Grandfather Clause..." . . . . . . . . . 
VII Subjects' Responses by Type of Basic Nursing Echucation Preparation to the Statement, "Registered Technical Nurses Should be Allowed to Enter Any...Professional Nurse Educational Program with Full Credit..." . . . . . . . . . . .

IX Subjects' Responses by Type of Non-Basic Nursing Education Preparation to the Statement, "Nursing. Should be Divided into Registered Professional and Registered Technical Nurses..." . . . . .

X Subjects' Responses by Type of Non-Basic Nursing Education Preparation to the Statement, "...The BacheIor's Degree should be Required for...a....Professional Nurse..." . . . . . . . . . . .

XI Subjects' Responses by Type of Nion-Basic Nursing Education Preparation to the Statement, Legislation Inplementing the Proposal Should Not Include a Grandfather Clause ................

XII Subjects' Responses by Type of Non-Basic Nursing Education Preparation to the Statement, "Registered Tecbnical Nurses Should be allowed to Enter Any... Professional. Nurse Educational Program with Full Credit..." . . . . . . . . . . . . .

XIII Results of Multiple Chi-Square Tests on Responses to the Four Facets of the Resolution by Type of role Organization Adopted by Nirrses ........... 
XIV Subjects' Responses by Type of Role Organization Adopted to the Statement, 'Nursing Should be Divided into Registered Professional and Registered Technical Nurses..." . . . . . . .

XV Percentage of Agreement with Two Levels of Nursing by Degree of Role Allegiances Expressed . . . .

XVI Subjects' Responses by Type of Role Organization Adopted to the Statement, "...The Bachelor's Degree Should be Required for .......Professional Nurse..." . . . . . . . . . .

XVII Percentage of Agreement with Bachelor's Requirement by Degree of Role Allegiances Expressed . . .

XVIII Results of Vultiple Chi-Square Tests on Responses to The Four Facets of the Resolution by Degree of Role Deprivation Expressed . . . . . . . . .

XIX Subjects' Responses to the Statement, "Nirsing Should be Divided into Registered Professional and Registered Technical hurses..." By Degree of Role Deprivation Expressed . . . . . . .

XX Subjects' Responses to the Statement, "... The Bachelor's Degree Should be Required for...a...Professional :irrse..." by Degree of Role Deprivation Expressed ....................

XXI Analysis of Variance for the Effects of Type of Education and Length of Woris Experience on Bureaucratic Allegiance . . . . . . . . . 
XXII Results of the Newman-Keuls Multiple Comparisions

Test on Bureaucratic Allegiance of Three

Groups with Differing Lengths of Work Experience. •

XXIII Analysis of Variance for the Effects of type of Eucation and Length of Work Experience on Professional Allegiance . . . . . . . . . .

XXIV Analysis of Variance for the Effects of Type of Education and Length of Work Experience on Total Role Deprivation . . . . . . . . . 102 


\section{LIST OF FIGURES}

1. Interaction of Type of Education Preparation and

Length of Work Experience on the Professional

Role Conception Mean Scores . . . . . . . 101 
CHAQTER I

INTRODUCTION

INTRODUCTION TO THE PROBLEM

One of the most persistent and crucial problems confronting organized nursing is the disagreement of its membership as to the type of educational preparation necessary for its practitioners. The issue of educational preparation for nurses and its practice implications has been a long-standing controversy among nurse educators, practitioners, and administrators. A number of factors have been considered and have failed to fully account for this lack of consensus.

This research examines the relationship of selected variables to nurses' views of the educational requirements for entry into professional nursing practice. The study does not purport to determine wat level of educational preparation is necessary to nursing practice, nor does it address the specific implications of any future changes in the levels of educational preparation of nurses. The current research findings may, however, serve to set the stage for other research examining such questions and implications. 
Any change in current educational and practice standards for nurses will have political, economic, and educational impact on the profession of nursing. Determination of the degree of support for change in educational requirements among nurses at large may be helpful to nursing leaders in developing political strategies within professional nursing groups and legislative assemblies to implement sich changes. Further, determination of the effects of nurses' views of their roles on the degree of support for change in educational and practice requirements may be useful to nursing educators who influence nurses' conceptions of their roles. Lastiy, the results of this study may be of assistance to educational administrators and employers of nurses in determining manpower needs for the future and in developing economic strategies for implementation of the proposed changes in educational requirements for nurses.

\section{The Background of The Study}

Many leaders within the field of nursing have held the educational requirement for professional practice must be a baccalaureate degree in nursing, because the nurse bears primary responsibility for assessing, prescribing, providing, and evaluating nursing care to clients with complex health care problems. Sheahan (1972) stated nurses earning a Bachelor of Science in Nursing acquire the 
theoretical foundations necessary for the professional practice of nursing, and there is a demand for nurses prepared at this entry level because of the increasing complexity of knowledge and skills needed to render care in today's bealth care arena (p. 440). McClure (1979) noted, "the quality of education is inextricably linked with the quality of practice" (p. 50).

Opposition to this educational requirement has prevented its adoption during the 70 years since it was first advocated by the national organization of nurse practitioners, now known as the American Nurses' Association. Mang nurses continue to disagree that baccalaureate preparation is necessary for entry into professional practice, despite studies by Brown (1948), Ginsberg (1948), Goldmark (1923) which criticized the state of nursing education in non-academic hospital schools of nursing and which recommended that colleges and universities serve as providers of nursing education programs.

Since little progress had been made in providing nursing students with advanced academic preparation, the American Nurses' Association in 1965 published a position paper advocating the housing of all nursing education programs in institutions of higher education and delineating two levels of nursing practice, technical nursing (to be provided by associate degree nursing programs in community colleges) and professional nursing (to be provided by 
baccalaureate nursing programs in four year colleges and universities) (Educational Preparation for Nurse Practitioners, 1965). The publication of the position paper did not lead to its adoption by the various states.

Disturbed that the controversy over educational preparation remained unresolyed, the Nep York Nurses' Association in 1974 passed a resolution which called for a deadine of 1985 to implement the American Nurses' Association's 1965 proposal for nursing education and practice in the State of New York (American Nurses' Association Convention '78, 1978). This 1985 deadline was subsequently adopted by the American Nurses' Association's House of Delegates in 1978 (Summary Proceedings, 1978). In that same year, the Oregon Nurses' Association's House of Delegates passed the resolution in Oregon (Harnetiaux, 1979; Lee, 1979d).

\section{A Conceptual Framework}

While there is some indication that a vested interest in one's own type of nursing educational preparation and length of work experience influence the individual's support or opposition to the 1985 Resoluticn, it is not sufficient to explain nurses' positions on the issue (Lee, 1979b, 1979d). Allen in Lee's report (1979a) and Estok (1977) indicated the lack of consensus among nurses regarding educationai requirements may be, in part, a result of 
conflicting values held by nurses. A conceptual framework, developed by Corwin (1960) and known as nurse role organization, which takes into account differing values held by nurses may serve to explain further why nurses tend to support or to oppose the 1985 Resolution and its related issues.

Corwin (1961a) determined that there is not one but at least three dominant conceptions of nursing - an office, a profession, and a calling. "These provide alternative identities for the nurse who is at the same time a hospital employee (or a bureaucrat), a responsible independent professional, and $z$ public servant..." (p. 606). Each of the three conceptions, bureaucratic, professional, and service role, encompass different and often conflicting values, beliefs, loyalties, and behaviors. Corwin (1960) and others (Kramer, $1968 \mathrm{~b}$; Taves \& others, 1963) have demonstrated that nurses maintain each of these role conceptions, and allegiance to each varies along a covtinum. These three conceptions place incompatible demands on the nurse. The potential for conflict is particularly evident between the professional and bureaucratic conceptions of role (Corwin, 196la, p. 606).

How the individual nurse reconciles the primary role conceptions in nursing is referred to as role organization. Role organization represents the relative allegiance which an individual expresses to the role conception values, 
considered jointly (Cormin, 1961a, p. 610).

How nurses organize their role conceptions leads to inherent disparities between iaeals and practice realities. Kramer (1968b) stated,

\begin{abstract}
Satisfactory enactment of a role is contingent upon a situation and a climate which the individual perceives as being favorable to role execution. When a situation is perceived as limiting the enactment of the role as conceived, the individual feels deprived of the opportunity to enact the role as he conceives of it. (p. 116)
\end{abstract}

Corwin (1965) referred to this phenomenon as role discrepancy. Role discrepancy "... is the extent to which an ideal conception of role is perceived to be impracticable" (p. 349). It represents the degree of conflict between the ideal role conception. (or what "should" be) and the reality in which nurses find themselves (or what "is"). Kramer (1968a) called this same phenomenon role deprivation. Depending upon the manner in which individual nurses organize their roles, they will experience varying degrees of role discrepancy or deprivation. Role deprivation has been found to be associated with professional disillusionment (Corwin, Taves, \& Haas, 1961).

Both the particular role organization and the degree of role deprivation influence nurses allegiance to the profession and its advancement (Corwin, 1960; Kramer, 1968b, 1970). This theoretical model has been useful in explaining nurses' dissatisfaction with their jobs, with the desire to 
change jobs, and with their decision to leave nursing entirely (Kramer, 1968a, 1971).

Since nurses differ in how they organize and reconcile their roles, discordant views on professional issues may result. Role organization aná role deprivation may be useful in distinguishing and explaining the degree of support nurses express toward the 1985 Resolution and its related issues.

\section{STATEMENT OF THE PROBLEM}

Though widely discussed in the literature, there has been little systematic study of the views of nurses regarding the proposal to require baccalaureate preparation for entíy into professional nursing practice. Knowledge of the extent of support for the so-called 1985 Resolution among nurses is limited. Further, their views on matters related to the resolution, such as articulation mechanisms among the various levels of nursing education programs, the proposed "grandfather clause" which would protect currently practicing nurses when the resolution becomes a reality, are not well understood.

Oregon is one of only seven states in the nation, and the only western state, in which the state nurses' association has passed the 1985 Resolution (Harnetiaux, 1979). The views of Oregon nurses regarding these issues are not clear (Teaff, Note 1). Further research in this 
area can contribute to a better understanding of the views of Oregon nurses related to the proposal, which, in turn, may be useful in the development of effective change strategies for implementing the resolution in Oregon.

The question raised is whether Corwin's constructs of role organization and role deprivation have utility in distinguishing and explaining differences among nurses' views toward professional practice issues of the 1985 Resolution? Though the model has been used to explain such phenomena as job dissatisfaction, employee turnover, and professional disillusionment, its efficacy in explaining nurses' views regarding the entry into professional practice has not been tested. Further, the effects of type of educational preparation and length of work experience on the degree of allegiance to bureaucratic and to professional role conceptions and consequent degree of role deprivation, which may influence nurses' views regarding the 1985 Resolution, are not known.

\section{THE RESEARCH QUESTIONS}

The study addresses the following six basic research questions:

(1) What are the views of Oregon nurses regarding select issues surrounding the 1985 Resolution? These issues include a professional/technical split in nursing practice, a baccalaureate requirement for professional licensure, a 
"grandfather clause" protecting currently iicensed nurses, and the ladder mechanism for articulation among nursing education programs.

(2) What are the relationships between selected demographic variables and the degree of support or opposition expressed by nurses to the 1985 Resolution and its related issues?

(3) What is the relationship between perceived role organization (Corwin's model) and nurses' views toward the 1985 Resolution and its related issues?

(4) What is the relationsbip between perceived role deprivation (Corwin's model) and nurses' views toward the 1985 Resolution and its related issues?

(5) Does the type of educational preparation and length of work experience affect the role organization of nurses? (6) Does the type of educational preparation and length of work experience affect the degree of role deprivation expressed by nurses? 
CHAPTER II

REVIEW OF LITERATURE

Literature to be reviewed includes the bistorical background of nursing education and practice, the conceptual framework of nurse role organization and role deprivation, and the several issues surrounding the entry into professional practice and the 1985 Resolution.

\section{HISTORICAL BACKGROUND}

Today, the profession of nursing is fragmented by three levels of nurse: professional (baccalaureate degree); technical (diploma or associate degree); and practical (licensed practical/vocational). The diploma, associate degree, and baccalaureate degree graduate share the identical license, that of Registered Nurse (R.N.). The practical nurse is licensed separately as a Licensed Practical/Vocational Nurse (L.P.N./L.V.N.).

This was not always the case in nursing. Waters (1978) reported that prior to World War II, 91 per cent of the nurses in the nation were diploma graduates of three year hospital schools of nursing (p. 2). The few practical nurses in the country were most often graduates of correspondence schools. It was not until 1947 that these two types of nurses were licensed separately, with the 
diploma school graduates being considered Registered Nurses and the practical nurses called Licensed Practical Nurses.

The demand for qualified nurses during Torld War I and during the post-war years encouraged the development of not onlg more programs of nursing education, but new types of programs and nurse practitioners. Until this time, Registered Nurses had to be primarily trained in hospital-based three year diploma programs, because relatively few baccalaureate nursing programs existed.

Since the vast majority of hospitals which supported diploma schools of nursing were privately owned, most often by physicians, the emphasis during the training period for nurses ras on the provision of service to patients, rather than an in-depth educational preparation of the nursing student. In order to maintain profits, it was necessary that the hospitals bave a steady supply of workers who saw to the daily care of their patients. Little attention was given to any formal educational activities for the students. Newer students learned as they could from senior year students, known as head nurses (Ashley, 1977).

Efforts to standardize nursing curriculum, provide formal course work, and house nursing education in institutions of higher learning by organized groups of nurses, such as the National League of Nursing and the American Nurses' Association, were met with serious opposition. Such opposition continued despite earlier 
finaings by Goldmark (1923) in which it was apparent that hospital schools of nursing were producing poorly educated and inadequately prepared nurses.

The most serious resistance to the efforts by organized nursing to upgrade nursing education came from the American Hospital Association and the American Medical Association, both of which exerted considerable influence on nursing education. Their sentiments regarding nursing education was aptly expressed in the following statement:

If a little knowledge is a dangerous thing in
most avenues of employment, in nursing it is
more than dangerous - it is fatal... Good nurs-
ing is not facilitated by too elaborate an edu-
cation in professional matters, rather it is
hampered or even rendered useless thereby...
(Ashley, 1977, p. 77)

The critical shortage of nurses after the war and the activities of organized nursing set the stage for major changes in nursing education. Studies by Brown (1984) and Ginsberg (1948) supported the housing of programs of nursing education in academic institutions. During this same time, the Carnegie Commission of Higher Education recognized the shortage of qualified health care personnel and urged that higher education become the main source for training such personnel.

The limited number of baccalaurate programs in nursing could not at the time provide the needed numbers of nurses. Further, the requirements for formal course work and qualified faculty then being demanded of hospital 
schools of nursing had driven up the cost of their nursing education programs to the point that many diploma programs began to close their doors.

A serious crisis in nursing manpower was averted with the advent of associate degree nursing programs, housed in the nation's community colleges. Under the guidance of Montag (1963), the founder of associate degree nursing, and with the support of the American Nurses' Association (Kinsinger, 1964) and the Kellogg Foundation (Anderson, 1966; Fields, 1962), numerous community colleges across the nation developed two year technical nursing programs.

Two Levels of Nursing

"The proposal for the technical nurse presupposed a strong core of truly professionally prepared nurse practitioners responsible for the quality and quantity of nursing care, working collaboratively with these new A.D.N. graduates" (Anderson, 1966, p. 283). Thus, the associate degree or technical nurse would have preparation beyond the practical nurse and would be considered a Registered Technical Nurse, but these nurses would work under the direction of a professionally prepared nurse, a Registered professional Nurse with baccalaureate education. The professional/technical split presupposed the closure of practical or vocational nursing programs and the eventual demise of this level of nurse, as mell as the closure of all 
diploma schools of nursing.

The technical nurse was envisioned to be one who could provide competent bedside nursing care, under the direction of the baccalaureate nurse. The practice of the associate degree nurse was to be directed toward patients in need of medical diagnostic evaluation, and/or who were experiencing acute or chronic illnesses. It was believed that such a nurse could be prepared to provide safe, technical nursing interventions, selected from established nursing protocols where probable outcomes are predictable, using the nurse's cognitive, psychomotor, and affective capabilities (Competencies of the Associate Degree Nurse, 1978, p. 3).

The professional nurse, prepared in baccalaureate programs, was identified as the leader of the nursing care team. Such a nurse was envisioned to be one who could provide not only highly skilled direct patient care, but also develop nursing protocols, supervise other nursing personnel, plan care to meet complex health care needs, serve as educator, and function in a variety of care settings, not merely hospitals. Further, the professional nurse was prepared to provide preventive as well as supportive and curative nursing care to a culturally diverse patient population and to function as a beginning researcher.

Though the American Nurses' Association in its 
initial support for the advent of associate degree nursing advocated two levels of nursing, technical (associate degree) and professional (baccalaureate), it has had no legal authority to force these changes. Such changes would require state legislators to enact into law these two levels of nurse licensure. The various state boards of nursing and the National League of Nursing would then have to establish accreditation standards for the programs, including curriculum, which reflect the technical/professional split.

The failure to enact the necessary changes for a technical/professional split, coupled with the failure to phase out practical/vocational nursing programs and diploma programs, has resulted in the current three levels of nursing practice: practical, technical, and professional. These levels reflect educational preparation of nurses of one year (practical/vocational programs), two years (associate degree programs), three years (diploma programs), and four years (baccalaureate programs). There has been no clear distinction made in practice or licensure between Registered Nurses prepared in the later three types of nursing programs. The result has been confusion and sharp disagreement among nurses as to the future course of nursing education and practice.

NURSING ROLE ORGANIZATION

Nursing role organization and role deprivation, using 
a model developed by. Corwin (1960), has been studied by Kramer (1968a, 1968b) and by Taves and others (1963) in relation to such factors as success in nursing, job satisfaction, and professional disillusionment. This conceptual framework may offer an explanation of why individual nurses tend to support or oppose the advancement of their profession. Role organization and role deprivation may serve to distinguish groups of nurses and help to explain why nurses maintain certain views about what should be required educational preparation for professional nursing practice and issues related to the 1985 Resolution.

Socialization to the role of aurse is an intricate and lengthy process, influenced by the education and experience of the indiviaual. Socialization may be defined as that mechanism whereby "...individuals acquire the knowledge, skills, and dispositions that enable them to participate as more or less members of groups..." (Brim \& Wheeler, 1966, p. 5). According to Elkin and Handel (1972), the individual, through socialization, learns the ways of a given group so that he/she can function within it (p. 4). Cotanch (1981) and Siegel (1968) indicated that socialization to a profession involves more than a mastery of selected skills and a body of knowledge. It also involves the incorporation of the norms, responses, values, and beliefs of the profession into one's personal system.

Over time, the student of the profession comes to 
define and identify with the occupational role. Brown, Swift, and Oberman (1974) have found that the socialization of nursing students to the occupational role is characterized by inner conflicts and ambivalence that may plague nurses years after their formal education is completed. The students must alter their lay image of rursing, as "angels of mercy", and develop an image or conception of the nurse as professional. As they make this transition, they are confronted with reconciling the "ideal image" of nursing presented by their nursing instructors (Corwin, 1961a; Hughes, 1956; Minehan, 1977) and the "reality image" exhibited by the nurses actually working in the hospital (Heidgerkin, 1970). Minehan (1977) noted that the students recognize the incongruities between the way they are taught to practice in their educational program and the way they are going to be expected to practice in the employment situation (p. 374).

Socialization for the career represents a transformation in status. Of primary significance in this passage is understanding and reconciling new conceptions, particularly of role, which create changes in the important perceptions, values, and beliefs of the individual (Corwin, $1961 a$, p. 604).

Taves and others (1963) defined role conceptions as those perceptions of the occupation that result from knowledge of the values and norms the person has learned are 
occupational expectations. Role conceptions refer to expectations about relationships among members of an organized group (Taves \& others, 1963, p. 1). Corwin and Taves (1962) indicated role conceptions, as images of the rights and obligations which the person perceives to be associated with the occupational position, are important for at least two reasons: "(1) They provide expectations which guide conduct (they indicate the appropriate behavior for particular situations), and (2) these guides generate attitudes - personal predispositions to act" (p. 223).

Studies by Corwin (1960), Cotanch (1981), Davis and Olesen (1964), Haberstein and Christ (1955), and Kramer, McDonnell, and Reed (1972) have indicated that there is more than one role conception held by nursing students and graduates. Corwin (1960) determined that three dominant conceptions were beld by nurses - an office, a profession, and a calling.

These provide alternative identities for the nurse who is at the same time a hospital employee (or a bureaucrat), a responsible, independent professional, and a public servant....Each identity provides a different course of loyalty to the local administration, to professional principles and associations that transcend the local place of employment, and to the patient ....There is reason to believe that the three ideal conceptions of nursing involve incompatible demands.... Potential conflict is particularly evident between the professional and bureaucratic conceptions of role. (Corwin, 1961a, p. 606)

The manner in which the individual chooses to reconcile the three primary role conceptions in nursing is 
referred to as role organization (Corwin, 1960; Corwin \& others, 1961). Role organization represents the relative degree of loyalty to each of the three role conceptions of professional, bureaucratic, and service, when considered jointly. Allegiance to each exists on a continuum from high to low. In Kramer's view, the role organization is the composite or configuration of the three role conceptions (1970, p. 430).

Corwin (1960) developed a three scale instrument, consisting of Likeirt-type items, which measures the intensity of each role conception held by nurses. His research indicated that nurses can be categorized as high or low on the scales corresponding to each role conception. He found bureaucratic and professional role conceptions to be particularly significant in determining the total role configuration or role organization. A high scale score indicates a bigh degree of acceptance of the principles constituting the scale. Respondents can be categorized on the basis of role organization into the following four groups: 1) nurses with high bureaucratic and high professional allegiances (HB-HP); 2) nurses with high bureaucratic and low professional allegiances (HB-LP); 3) nurses with low bureaucratic and high professional allegiances (LB-HP); or 4) nurses with low bureaucratic and low professional allegiances (LB-LP). 


\section{Service Role Conception}

The most basic role conception held by nurses is that of calling or service. The service role conception embodies traditional nursing values of care and concern for the patient, of humanitarian service to society. The allegiance in this role conception is, first and foremost, to the patient. In his study, Corwin (1960) found that nursing personnel did not differ significantiy in the degree of allegiance to the service role conception when two levels of education (diploma and baccalaureate) were compared ( $p$. 239). In a longitudinal study of baccalaureate graduates, Kramer (1968a) reported the mean change in service role conception score or degree of allegiance to the service role expressed by the subjects was not significant (p. 462). These studies would seem to indicate that nurses with differing types of educational preparation and length of work experience do not appear to differ significantly in their degree of allegiance to the service role conception.

\section{Bureaucratic Role Conception}

The bureaucratic role conception is also beld by nurses (Corwin, 1960, 1961b; Corwin \& Taves, 1962; Kramer, $1968 \mathrm{a}, 1968 \mathrm{~b}, 1970)$. It represents a second historical role in nursing. Once nursing became an organized office, institutions were developed in wich its art and science could be practiced. Nurses with only rare exceptions are 
employed in organizations, and hospitals continue to be the primary emplogers of nurses. Thus, there exists among nurses a loyalty to the organization in which they practice. The bureaucratic role conception is derived from the bureaucratic system of work organization and is based on the notion that it is more efficient to sub-divide a task among morkers specially trained for a segment of the task (Kramer, 1971, p. 57). As Kramer and others (1972) have noted,
because of the magnitude of the job to be done in the health care system and the limitations imposed by budget and public expectations, the hospital concerns itself primarily with the organization, maintainence, and delivery of efficient...health care... To accomplish this, the hospital follows the tenets of the bureau- cratic work system, dividing the total task among its many workers .... (p. 113)

This leads to the development of routine procedures, the need for supervisory coordination, and hierarchical controls (Kramer \& others, 1972 , p. 113).

Bureaucratic role conception, according to Cormin ( $1961 \mathrm{~b})$, refers to administrative rules and regulations which describe the nurses' jobs in a specific institution. In nurses' minds, it defines the scope of their practice in relation to patient care. Its values include adherence to the goals of the organization and the seeking of rewards provided by the organizational system.

In a study of diploma and baccalaureate nursing students and diploma and baccalaureate graduates, Corwin (1960) attempted to demonstrate differences in degree of 
allegiance to the bureaucratic role conception between the two groups, students and graduates, on the basis of type of educational preparation. He found that diploma students do have significantly higher bureaucratic conceptions than baccalaureate students, suggesting that the hospital schools of nursing produce greater loyalty to the hospital organization than do collegiate schools (p. 239). However, Corwin (1960) found that significant difference in bureaucratic allegiance disappeared among graduates of the two types of programs. His explanation was that baccalaureate nurses become more bureaucratically oriented after graduation (p. 239). Kramer (1970) in a study of baccalaureate nurse graduates confirmed Corwin's findings (1970) of increased bureaucratic allegiance pork experience.

\section{Professional Role Conception}

The last role conception to develop historically in nursing is that of professional. The professional role conception is derived from the professional system of work organization which, according to Kramer (1971), "...is based on the premise that the worker performs a whole task" ( $p$. 57), such as providing individualized, comprehensive patient care. The achievement of the necessary degree of skill and knowledge requires a lengthy training period and leads to other effects, such as operational autonomy, the desire for 
collegial control, and internalized standards of behavior (Kramer, 1971, p. 57; Kramer \& others, 1972, p. 113). Characteristics of this conception include spontaneity, autonomy, creativity, and resistance to conformity.

The principles of the professional role conception transcend the location of a specific work environment. Combs (1965) stated that in the professional role, the nurse uses the self and the body of knowledge of the occupation and its skills to solve the problems for which one is primarily responsible. The professional role conception suggests primary allegiance to the nursing profession and the activities of the professional organization (Corwin \& Taves, 1962, p. 223; Kramer, 1970, p. 430; and Kramer \& others 1972, p. 115). McManus (1949) has suggested that in the professional role the individual values intellectual achievements, exercises discretion in judgment, and resists standardization in production time. Goss (1961) and Miller (1967) have indicated in the professional role the individual, above all, strives for a utonomy and independence in the work setting.

Brown and others (1974) have found that professional attitudes tend to become stronger with length of stay in an educational program. However, Corwin (1960) reported no significant difference in the degree of allegiance to the professional role, based on group mean scores, when comparing diploma and baccalaureate degree students and when 
comparing diploma and baccalaureate degree graduates ( $p$. 239 ). In a later study, Cormin (1965) reported baccalaureate graduates did adopt a high degree of allegiance to the professional role conception more frequently than did diploma graduates (p. 352 ).

The Organization of Nursing Roles

The way in wich nurses reconcile the three role conceptions is referred to as role organization by Corwin (1960) and Corwin and others (1961). In his research, Corwin (1960) found the bureaucratic and professional role conceptions to be particularly significant in determining nurses' total role configuration. He and others (Corwin \& others, 1962; Kramer, 1968a, 1968b; Kramer \& others, 1972) distinguished nurses' role organization on the basis of degree of allegiance expressed simultaneously to the bureaucratic and the professional role conceptions.

Corwin and Taves (1962) identified two mechanisms a work in the socialization of nurses to their roles, which they labeled "professionalization" and "bureaucratization". Professionalization is the mechanism whereby an occupation gains a monopoly of specialized knowledge and skills. In aursing, it requires that the nurses' attention be directed toward the maintainence of educational and professional standards. This is accomplished by reading professional literature, continuing one's education through workshops and 
courses, participation in professional committee work, and participation in national, state, and local professional associations (Corwin \& Taves, 1962, p. 223).

Bureaucratization suggests the work setting as a source of loyalty for the nurse. It is the mechanism, in the words of Corwin and Taves (1962), "...through which the virse tás becoule incorporated into a large scale organizational system, thereby increasing the.nurse's administrative and technical duties" (p. 223).

The two mechanisms and the systems from which they are derived represent, according to Rosenberg, Suchman, and Goldsen (1957), encroachments upon each other, and as such, potential for internal conflict is inevitable. Getzels and Guba (1954) explored such conflict and stated that ohen an individual is confronted with carrying out multiple roles that may be contradictory or hold mutually exclusive expectations, the person is forced to attempt a compromise among the roles.

Thus, nurses holding multiple role conceptions are continuously subject to contradictions and compromise in their practice. This awareness of.role conflict dramatically increases after graduation, when shifts in allegiance from school to the mork organization are forced (Corwin, 1961a, p. 605). Corwin (1965) made comparisons between his two primary groups of subjects, students and graduate nurses, consisting of diploma and baccalaureate 
prepared individuals, and concluded there are differences in how groups of nurses organize their roles. Role organization among the two types of nursing student was not found to be significantly different. It appeared that diploma and baccalaureate nurses experience conflict and change in role configuration only after graduation (1965, p. $353)$.

Corwin (1965) found that while degree nurses were less Iikely. to hold high bureaucratic and low professional allegiances, this was a more frequent choice among diploma nurses. Further, baccalaureate nurses expressed high bureaucratic-high professional or low bureaucratic-high professional allegiances more frequently than did diploma nurses ( $p .352$ ).

\section{Role Deprivation}

Etzioni (1969) supported the contention that there exists in nursing an inherent tension between the professional principles and the organizational ones (p. 8). This conflict is not unique to nursing. Numerous studies (Becker, 1953; Ball, 1976; Bullough \& Bullough, 1971; Miller, 1967) have shown this to be the case for many occupational groups. It is, however, more appareit and ritualized in human service organizations, such as hospitals, according to Hasenfeld and English (1974) and Weisbord (1976). 
Sätisfactory enactment of a role requires.a climate favorable to its execution. When a situation is perceived as limiting the enactment of the role conception, the individual feels deprived of the opportunity to carry out the role as perceived as necessary (Kramer, 1968b, p. 116). Corwin (1965) referred to this as role discrepancy, or "...the extent to which an ideal conception of role is perceived to be impracticable" (p. 349). Corwin's role organization instrument (1960) is designed to yield a discrepancy score, which is the difference between the respondent's statement of what should be the case (ranging from "strongly agree" to "strongly disagree") and the individual's statement of what is the case (also ranging from "strongly agree" to "strongly disagree") (p. 349). Kramer and others (1972) labeled this same phenomenon role deprivation and defined it as the disparity between the way things are perceived as being in nursing practice and the way it is thought they ought to be in nursing.

Studies by Kramer $(1970,1971)$ and Kramer and others (1972) indicate that a high degree of role deprivation is associated with nursing job turnover, job dissatisfaction, and the post-graduate exodus from nursing practice. Corwin and others (1961) stated that a high degree of role deprivation can result in progressively dislogal statements about the profession and professional disillusionment. Corwin (1960) has reported that the nurses' statements of 
discrepancy between ideal and perceived reality is a statement of their desire for change in the status quo ( $p$. 23).

In his study, Corwin (1965) found that persons who beld both high bureaucratic and high professional a llegiances expressed the highest degree of role deprivation. Those who had low bureaucratic and low professional scores expressed the smallest discrepancy in roles. He also reported that persons with low bureaucratic and high professional allegiances experienced higher discrepancy scores than did persons 1 ith high bureaucratic and low professional allegiances. There is also some evidence, presented by Kramer (1969), Miller (1967), and Tetreault (1976), which suggests that the sense of role deprivation may increase with time in the job.

\section{THE 1985 RESOLUTION}

The 1985 Resolution on Entry into Professional Practice was initiated by the New York Nurses' Association and subsequently adopted by the American Nurses' Association in 1978. It has since been adopted by the Oregon Nurses' Association's House of Delegates. The resolution is presented below:

Whereas, The existence of multiple kinds of basic nursing education programs leading to licensure as a registered professional nurse creates immeasurable public and professional confusion, and 
Whereas, It has also long been recognized that baccalaureate preparation is basic to professional nursing practice,

Therefore $B \in$ I $i$ Fesolved, That the...Association develop a plan establishing by 1985 the baccalaureate degree in nursing as a requirement for licensure as a registered professional nurse, and be it further

Resolved, That this effort provide through grandfather clauses and/or other appropriate means, full protection of all practice privileges, titles and status of all individuals currently licensed or preparing for licensure as a registered professional nurse. (McClure, 1976, p. 13)

Much has been written about the advantages and disadvantages of a professional/technical differentiation in the types of nurse practitioners. The original intent of the associate degree nursing program was to provide technical nurses for the work force aud replace both practical and diploma nurses with such a practitioner. However, during the nearly 30 years since the first associate degiee nursing programs were developed, the original intentions and the philosophical base of the professional/technical split has become distorted, if not lost entirely, according to Bensman (1977), Hogstel (1977), Montag (1970), and Rotkovich (1976). This has set the stage for widespread disagreement among nurses as to the need for differentiation in practice levels and licensure.

\section{Professional/Technical Differentiation}

MacPhail (1978) indicated that the changing character 
of the nation's health care needs demand that the current character of nursing change. Nursing leaders state that future bealth care needs will dictate a national pool of nurses in which 50 per cent have a technical preparation, 40 per cent have entry level professional preparation (baccalaureate degree), and 10 per cent hold a master's or doctoral degree (Entry into Practice, 1978; Scott, 1979). MacPhail (1978) noted,

In the past decade, an increased demand for and utilization. of health care services has precipitated a major concern about the "health manpower crisis"....Responses to this concern have led to the development and proliferation of many technical and professional roles in the health care system... This lack of planning has led to fragmentation, duplication, and gaps in service.... No longer can the bealth care system support a continued increase in the numbers and kinds of bealth care providers without being equally concerned about the goals for providing care, the quality of care. the cost of care, and priorities for health care. (p. 28)

A recent article in the Journal of Nurse-Midwifery summarized the benefits to society in differentiating two levels of nursing practice. The enactment of the resolution would serve the public in the following ways:

1) The increased knowledge base and research skills attained through baccalaureate education would enable a profession to meet changing social demands and to advance its practice.... 2) A university based education would minimize the sexist and paternalistic foundation of nursing and replace it with an autonomous broadened base....3) No other health profession requires less than a university program for entry and such an educational requirement advances the 
profession as a whole...4) A clear definition of different qualifications and responsibilities of different types of nurses would serve the public interest and provide for more effective use of resources. (The 1985 Proposal, 1980, p. 1)

Katz (1969) and Simms (Two New York Nurses Debate, 1976) Stated enactment of the resolution will professionalize nursing. Lee ( $1979 \mathrm{~b})$ reported in a poll of approximately 10,000 nurses fully one-third of the respondents who indicated they supported enactment of the resolution stated they believed the profession would be advanced as a result.

There has been little in the way of systematic study of the views of nurses regarding the professional/technical differentiation suggested in the 1985 Resolution. The only major study to date has been that of a polling of the readership by RN Magazlne in 1978 (Special Poll, 1978). of approximately 10,000 nurses who responded, 72.7 per cent expressed opposition to the differentiation in practice and licensure proposed î̀ the resolution (Lee, 1979b).

Lee $(1979 b)$ reported that nearly 35 per cent of the poll respondents under the age of 25 expressed support for the resolution, while only 21.5 per cent of those over the age of 45 did so. Approximately 38 per cent of the respondents who were members of the American Nurses' Association, as compared to 21 per cent of the subjects who were not, indicated theg supported the resolution. 
Seventy-eight per cent of the head nurses or supervisors and nearly 75 per cent of the hospital staff nurses responding to the poll were opposed to the professional/technical differentiation. Fifty-seven per cent of the nurse respondents who held advanced academic preparation in a field other than nursing supported the two levels of nursing. Of the nurse educators who responded to the poll, 46 per cent were in favor of the resolution. Twenty-seven per cent of the baccalaureate degree nurses and 80 per cent of the associate degree and diploma nurses in the poll expressed their opposition to the two levels of nursing.

A major reason for opposing the resolution was expressed by nurse respondents in the poll reported by Lee (1979c). This is the current fallure to differentiate practice for technical and professional aurses in work settings. In a study conducted by Kohke (1973), one-half of the deans of nursing indicated that the curriculum for preparing technical and professional nurses had become blurred and that differences in practice were in actuality few. It is well known that hospitals, with few exceptions, have failed to restructure nursing practice since the advent of associate degree programs. Consequently, there has beeu a widespread failure to fully utilize the two levels, as originally envisioned by the profession.

Baccalareate nurses, therefore, are not able to function at their highest possible level (DeChow, 1971; 
Fabayo, 1980; Rotkovich, 1976). According to DeChow (1970), Montag (1972), and Rotkovich (1976), technical nurses have been placed in the stressful position of attempting to perform at a level for which they are ili-prepared. Since this current structure of hospital nursing has not permitted differentiation in levels of nursing practice, hospitals rarely differentiate levels of salary based on academic preparation.

\section{Entry Requirement for Professional practice}

The 1985 Resolution calls for a baccalaureate degree in nursing as the minimal requirement for professional practice. Martinson offered the following rationale for baccalaureate preparation as an entry level requirement:

- The outlook of the BSN nurse is broadened through the in-depth addition of sociological and psychological concepts, as mell as study of the fluiranitiss ....Her scope of nursing includes not only recovery from illness, but also disease prevention and the promotion of health, thus increasing not only the variety of settings in which she's prepared to practice, but also the levels of health care she is prepared to provide. (Lee, 1979a, p. 65)

Further, del Bueno stated,

If nurses wish to achieve the status of true professionals, if they wish to participate equally in decisions regarding bealth care, if they wish to be recognized as health workers who can be directly reimbursed for their services, and if they wish to reduce confusion in the public's perception of the nurse, then there can be no disagreement with the need to establish the baccalaureate degree as the basis of entry into nursing practice. (Lee, $1979 a$, p. 65) 
It is the position of the American Nurses' Association's Commission of Nursing Service that the

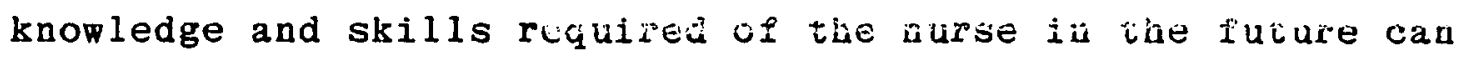
be achieved cniy in a college or university and will require at least a baccalaureate degree. Such preparation will provide the scientific and humanistic background and the problem-solving and decision-making skills essential for beginning professional practice (McGlothlin, 1964, p. 26). Cleland (1978) was in agreement that nurses prepared at the professional level are able to function in multiple health care settings with a major degree of self-direction.

There is little research data available to determine the degree of support for the baccalaureate degree as the entry level requirement for professional practice. Lee (1979c) reported that nearly 50 per cent of the nurse respondents in the RN Magazine poll indicated they favored the baccalaureate requirement, should the resolution be enacted.

In the study reported by Lee (1979d), opposition to the baccalaureate degree as the entry requirement for professional practice by at least some of the respondents appeared to stem from a fear that this would adversely affect their own status and prestige, as non-baccalaureate degree-holders. One nurse summed up her concerns by saying, "...lets not turn nursing into a snobby, white collar elite and a group of lower-ranking teounicians" (Lee, 1979d, p. 


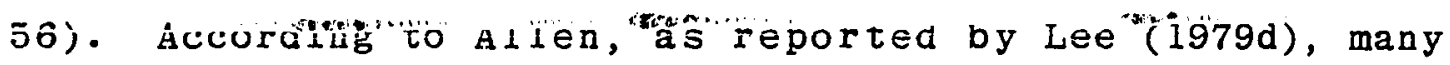
nurses seem to feel this aspect of the resolution is a direct threat and seem unable to set aside their personal needs and biases for the future good of the profession.

Meyer (1977) offered another potential reason for nurses' opposition to this requirement, and that is the lack of objective proof the baccalaureate nurse offers improved care to patients. This is a sentiment echoed by others (Educational Preparation of Nurses, 1980).

Another reason for opposition to this requirement was cited by nurse respondents in the RN Magazine poll. A number of subjects reported they believed this requirement would result in a shortage of professionally prepared nurses (Lee, 1979d). Dyer (1979) and Meyer (1977) bave made this same prediction, in spite of the fact that today over 30 per cent of new graduates in nursing are prepared at the baccalaureate level (Educational Preparation for Nursing 1978, 1979).

A further reason for opposition to this requirement has been cited by the American Association of Community and Junior Colleges, as reported by Lee (1979d). Because community and junior colleges have been more successful than baccalaureate programs in recruiting men, minorities, older students, and those students $\mathbb{i}$ th less academic preparation and fewer financial resources (Bayer, 1973; Foss \& Whipple, 1973 ; Haase, 1978), there is concern that access to 
professional nursing programs will be limited for these persons.

\section{The Grandfather Clause}

The American Nurses' Association and its state associations have consistently supported inclusion of the "grandfather clause" in the resolution to protect currently licensed nurses (Harnetiaux, 1979; Proceedings of the Forty-Second Convention, 1960). Littie is known of how the nation's nurses view this protective clause. Lee (1979c) reported in his poll of the readership of RN Magazine that one-third of the 10,000 nurse respondents stated they were opposed to a "grandfather clause". Singleton (1979) suggested that assuring a professional level of nursing practice would require those nurses currentiy prepared in diploma and associate degree programs to upgrade their knowledge and skills through formal education programs before they are granted professional stature.

\section{The Ladder Mechanism}

The 1985 Resolution provides "...through grandfather clauses and/or other appropriate means, full protection of all practice privileges, titles and status of all individuals currently licensed or preparing for licensure..." (McClure, 1976, p. 13). Mang nurses interpret 
the statement of "other appropriate means" to include such measures as the ladder approach to nursing education. McGriff (1980) noted that an adequate system of articulation among the various types of nursing programs, such as that afforded by implementation of the ladder approach, will make the 1985 Resolution palatable to greater numbers of nurses.

The ladder approach or open curriculum, envisioned by Combs (1965) and Katzell (1970), in nursing is a system which takes into account the differing purposes of the various types of programs in nursing and permits students mobility from practical nursing through graduate education. It assumes transferability of credits from one level of education to another.

The ladder concept of nursing education has been widely adrocated among nurses (Boyle, 1972; Ingles, 1971; Koffman \& Andruskit, 1971; Wood, 1973). Indeed, the overwhelming majority of respondents in the study reported by Lee (1979c) endorsed the approach. Ninety-one per cent of his subjects indicated that when the resolution is enacted, a technical nurse should be allowed to enter a professional nursing education program with full credit given for previous education.

Not all nurses agree that a career ladder should exist. Wooley (1978) reported that many nurse educators and practitioners state that since the technical and professional approaches to nursing are so different and the 
identity change required of such great proportions, it is necessary for the student to start over from the beginning, in order to gain the desired perspective and theoretical framework necessary to professional nursing practice. Montag (1970), Moore (1972), and Petrone (1978) agreed that associate degree nursing represents a terminal degree, the credits for which should not be viewed as transferable to a baccalaureate program.

Through widely debated in the literature, there has been little systematic study of the views of nurses regarding the ladder mechanism. A need for further research in this area is apparent.

\section{CONCLUSIONS}

The lack of systematic research on the views of nurses regarding the 1985 Resolution and its related professional issues thwarts attempts by organized nursing to develop effective strategies and garner support for implementation of the resolution. The current research is aimed at providing additional data, systematically collected, on the views of Oregon nurses related to these issues.

Though previously used as a model to distinguish groups of nurses and explain differences among nurses in relation to job turnover, job satisfaction, professional disillusionment, and rate of exodus from nursing, Corwin's 
model of role organization and deprivation has not been tested for its utility regarding professional advancement issues. The current study attempts to determine the relationship of aurse role organization and role deprivation to the degree of support for the 1985 Resolution and its related issues among Oregon nurses. Further, this study explores the relationship of type of educational program and length of work experience to the variables of professional and bureaucratic allegiances and to role deprivation. 
CHAPTER I I I

\author{
METHODOLOGY
}

DESIGN

\begin{abstract}
The research design was that of a descriptive ex post facto study. Information was collected from a sample of Oregon nurses using a mailed questionnaire. The four research objectives were: 1) to determine the views of Oregon nurses regarding the 1985 Resolution and its related issues; 2) to determine the relationship of certain demograph variables to nurses' views of the 1985 Resolution and its related issues; 3) to explore the relationship of role organization and role deprivation experienced by nurses to their views of the 1985 Resolution and its related issues; and 4) to examine the effects of type of educational preparation and length of work experience, jointly and Independently, on nurses' expressed allegiance to bureaucratic and professional roles and on the degee of role deprivation expressed by nurses.
\end{abstract}

\title{
SUBJECTS
}

Four hundred currently licensed Registered Nurses in Oregon, with Oregon addresses and selected at random (using 
each 58 th name), were drawn from the alphabetical mailing list of 23,250 nurses registered in Oregon by the state Board of Nursing. The list was entered at random. Three hundred of the four hundred nurses selected were asked to participate in the study through a mailed questionnaire and through follow-up mailings. (See Apprendix A) To obtain this sub-sample, the list of 400 nurses was entered randomly, and every other name was selected until a new list of 300 was obtained. The remaining one hundred potential subjects were held in reserve to be used as substitutes, should ang of the mailed questionnaires be returned to the researcher as "undeliverable" because of subject relocation with no forwarding address.

\section{INSTROMENTATION}

The data were obtained utilizing three instruments: a demographic data sheet; a modification of Corwin's "Role Organization" instrument (Corwin, 1960); and a questionnaire, "Views Toward the 1985 Resolution", devoloped by the researcher.

\section{Demographic Data Sheet}

Selected demographic characteristics of the sample are reported by frequency and percentage of occurence for descriptive purposes. The descriptors included the 
following: sex; age; level of basic nursing education; highest level of nursing education attained beyond basic preparation; highest degree held outside of nursing; number of years of nursing experience; membership status in the American Nurses' Association; employment status; and type of institution in which the subject was currently employed. (See Appendix B)

\section{Role Organization Instrument}

Corwin's original 22-item instrument was reduced to a 14-item instrument by eliminating the service role conception scale, one of the three scales used in the original instrument. The scale was eliminated because it had been found to be non-significant in distinguishing nurse role organization among groups of nurses (Corwin, 1960, Қramer, 1968a).

The resulting 14 items constitute two Likert-type scales designed to assess bureaucratic and professional role conceptions. Items which are thought to be representative of basic themes of each concept are stated as relevant hypothetical situations in nursing (Corwin, 1965, p. 349). (see Appendix B)

The items were selected on the basis of their relevance to ideas implied in the concept of bureaucrat and professional (Cormin \& Taves,) 1962). "Consequently, while the items do not necessarily represent all dimensions of the 
concept - i.e. the scales are not exhaustive - the items selected are supposed to be relevant to the concept" (Corwin, 1960, p. 205).

The items are stated in the form of hypothetical situations in mich nurses may find themselves. The subjects are asked to indicate the extent to which they think each situation should be the ideal in nursiñ by checking a response from "strongly agree" to "strongly disagree" (Corwin, 1960, p. 205). The use the hypothetical situations allows simplification of actual complex situations by abstracting random details from the situation (Corwin, 1960, p. 215)

In this way certain characteristics of the situation which are of interest to the investigator may be examined independently of irrelevant circumstances.... The statement is of interest because it is relevant to nurses' value system not because it predicts... actual behavior... (Corwin, 1960, p. 215 ).

The bureaucratic conception of role scale (BRC) consists of six items which include such characteristics as punctuality and strict following of rules (Corwin, 1965, p. 349). The scale assesses reported loyalty to the work system reflected in such practices as adberence to regulations and rewards based on conformance to the bureaucratic operation (Kramer \& others, 1972, p. 115). Possible score range is six to 30 .

The professional conception of role scale (PRC) consists of eight items which include commitment to 
knowledge as the basis of a profession and the ability to use power and judgment to make decisions about nursing practice (Corwin, 1965, p. 349). The scale assesses degree of loyalty to the tenets of the professional system, such as valuation of collegial control, autonomy, and continued self-education (Kramer \& others, 1972, p. 115). Possible score range is eight to 40 .

The wording of the statements to which subjects were asked to respond was modified slightly from Corwin's original questionnaire in order to permit nurses, regardless of the type of setting in which they were currently employed, to respond. Thus, statements in Corwin's instrument ending with "in my hospital" were modified to read "in my experience". This modest deviation from the original instrument ensured that all respondents would feel free to answer the item, regardless of place of current employment, since virtually all nurses have had experience in hospital nursing。

A final modification of the instrumeri was made by altering the (A) and (B) narrative situations in each item to read as declarative statements, rather than as questions posed in the original instrument. This change did not alter the content of the items but was done to better fit a Likert-type response pattern.

By checking one of the alternative responses on a five point Likert scale, ranging from "strongly agree" to 
"strongly disagree", the respondents indicate the extent to which the situation should exist in nursing. The arithmatic sum of responses weighted from five for "strongly agree" to one for "strongly disagree", constitutes the Total scale Score for each of the role conceptions of each of the subjects (Corwin, 1965, p. 349). The weighting of items nine and 16 is reversed. A high mean indicates high role conception scale scores for a group of subjects (Corwin \& Taves, 1962, p. 224).

The configuration of scores on the two scales represents the respondents' role organization. Corwin (1965) defined role organization as "...the relative allegiance which an individual or group expresses to the bureaucratic and professional roles, considered jointly" (p. 350). The respondents' scores on the bureaucratic and on the professional scale are divided at the mid-points of the respective distributions, and each respondent can, then, be classified as either "high" or "low" on both scales, with a

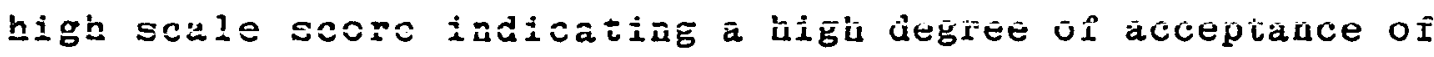
the principles constituting that scale (Corwin, 1965, p. 350). Thus, respondents may be classified into four groups: 1) high bureaucratic-high professional allegiance; 2) high bureaucratic-low professional allegiance; 3) low bureaucratic-bigh professional allegiance; or 4) low bureaucratic-low professional allegiance (Corwin, 1961b, p. 610). 
The instrument also measures role discrepancy or deprivation. Role deprivation is the extent to which an ideal conception of role is perceived to be impracticable (Corwin, 1965, p. 349). In other words, it is the disparity between the way nursing practice is perceived to be in reality and the way nurses believe they should be able to practice (Kramer \& others, 1972, p. 115).

The discrepancy score is the difference between the respondent's statement of what should be the case (ranging from strongly agree to strongly disagree) and his perceptiou of what is actually the case for each statement in the same scale (also ranging from strongly agree to strongly disagree). (Corwin, 1965, pp. 349-350)

The respondent's discrepancy or deprivation score is derived from the arithmatic sum of differences betreen weighted responses to normative and reality perceptions for each statement (Corwin, 1965, p. 350).

For example, a "strongly agree" response to the normative portion of the statement is given a weight of five, while a "disagree" response to the descriptive portion is given a weight of two. The discrepancy score is three. (Corwin, 1965 , p. 350)

The possible difference score for each item is zero to four. A high deprivation score indicates a high degree of role deprivation for each scale (Corwin \& Taves; 1962, p. 225). Further, since + and - discrepancies are considered to be different only in kind, the signs are ignored in the summation of the items for a Total Role Deprivation Score for the instrument (Kramer, 1968a, p. 463). The possible 
score range is zero to 56.

It cannot be assumed that the scoring method adopted elicits an actual measure of intensity of agreement, since this would require a standard unit of measurement and common knowledge of the belief system of the respondents...Responses, therefore, cannot be interpreted as a measure of existing agreement in the general nurse population - only as a measure of respondent's judged relationship to other respondents ....It is a measurement of how respondents think they compare with other respondents on intensity of agreement with the statement....This is an important kind of knowledge if it is assumed that the respondent's estimate of his respective position on issues influence his behavior. (Kramer, 1968a, p. 464)

In developing and testing his instrument, Corwin (1960) reversed the order of normative and descriptive statements on two forms of the tool to determine if the first statement influenced the response to the second statement. He found there were no significant differences in the responses on the two forms "... which indicates that a prior response to either the 'should' or the 'is' statement does not consistently influence the response to the other statement" (Corwin, 1960, p. 216)

Kramer (1970) investigated the validity of Corwin's scales by testing them against the external criterion of "known groups", using a group of nurses known to possess a high professional orientation (baccalaureate nursing faculty) and a group of nurses known to possess a highly bureaucratic orientation (hospital nursing supervisors). She reported that critical ratios between mean scale scores of the two "known groups" were significant at .05 alpha 
level which led her to conclude satisfactory validity.

Kramer (1968a) studied the validity question in terms of behavioral criterion for the role deprivation scales. She found that two groups of nurses she predicted to be at the extreme of the role deprivation continuum on the basis of behavioral criteria, such as frequent job change, absenteeism rate from work, and supervisory reprimands for rule infractions, did score significantly different in the predicted direction on the role deprivation scales (p. 464).

Corwin (1965) investigated the reliability of his instrument and reported the following:

Each item was pretested for internal consistency. Discriminatory power was measured for each item by computing critical ratios between upper and lower quartiles based on respondent's total scores for each scale. Only items reaching the five per cent level of significance were retained. (p. 349)

Kramer (1970) studied the reliabllity of Corwin's instrument by the test-retest method at three week intervals on a sample of 52 senior baccalaureate nursing students. The study yielded the following reliability coefficients: .89 on the bureacratic scale; .88 on the professional scale; and .86 on the role deprivation scale (p. 432).

In the current research, coefficient alpha was used to test the reliability (internal consistency) of the following three scales of the instrument developed by Corwin (1960): bureaucratic role conception scale (BRC); professional role conception scale (PRC); and total role 
deprivation scale (TRD). "Coefficient alpha sets an upper limit to the reliability of tests constructed in terms of the domain-sampling model" (Nunnally, 1978, p. 230). Coefficient alpha was calculated in this study using method two (Hull \& Nie, 1979, p. 131) of the ANOVA Subprogram Reliability in the S.P.S.S. computer package (Huil \& vie, 1979, p. 115). Coefficient alpha for the bureaucratic conception scale was found to be 0.53716 . For the professional conception scale, it was 0.48475 . Using the absolute difference scores for the total role deprivation scale, coefficient alpha was found to 0.76425 . Since the range of scores and the number of items was small, a low alpha was not unexpected (Downie \& Heath, 1970, p. 247) and did not alter the interpretation of the data.

\section{Views Toward the 1985 Resolution Instrument}

The four item questionnaire, "Views Toward the 1985 Resolution", measures respondents' expressed degree of support for two levels of nursing practice, as defined in the 1985 Resolution, for the baccalaureate requirement for professional practice, for the granting of credit for all previous nursing education (ladder mechanism of articulation between nursing programs), and for the "grandfather clause", associated with the 1985 Resolution.' The items were selected from among those which appeared in a poll of nurses taken by RN Magazine in 1978 (Special Poll, 1978). The 
response pattern was converted from dichotomous categories found in the original instrument to a four point Likert-type scale.

Scoring of the four items is on a scale of four (for "strongly agree") to one (for "strongly disagree"), with the weighting for questionnaire i teü taree reversed. The higher the respondent's score for each item, the greater support the respondent expresses in relation to that item. (See Appendix B)

\section{PROCEDURES}

The three instruments were combined into a single questionnaire with an accompanying cover letter. Three hundred Registered Nurses were mailed questionnaires in the spring of 1982 . Five questionnaires were returned as "undeliverable" with no forwarding address. Therefore, five substitutions were made, taken from the reserve pool of 100 .

Two bundred and fifty-two of the 300 subjects returned completed questionnaires. A response rate of 84 per cent was achieved, using a careful follow-up procedure. In response to the initial mailing, 160 completed questionnaires were returned. A follow-up letter to non-respondents one and a half weeks after the date of the original mailing fielded an additional 47 completed and returned questionnaires. A second follow-up letter, 
accompanied by another copy of the questionnaire, was mailed to non-respondents three weeks after the date of the original mailing. This garnered an additional 45 completed questionnaires. (See Table I)

TÁBLE I

THE NUMBER AND PER CENT OF COMPLETED QUESTIONNAIRES

RETURNED IN RESPONSE TO EACH OF THREE MAILINGS

\begin{tabular}{lccc}
\hline & Date & $n$ & per cent \\
\hline Initing & Marcb 29, 1982 & 160 & 63.5 \\
First Follow-up & April 9, 1982 & 47 & 18.65 \\
Second Follow-up & April 17, 1982 & 45 & 17.85 \\
Total & & 252 & 100.00 \\
\hline
\end{tabular}

In instances where more than eight responses of the possible 40 (or 20 percent of the response data) were missing from the questionnaire, the subject's questionnaire was discarded. Two hundred and thirty-two of the 252 questionnaires were without missing responses. Eleven questionnaires were missing from one to eight responses. Of 252 subjects, five failed to provided more than eight responses. The result was a total of 247 usable questionnaires. 


\section{STATISTICAL METHODS}

Data were computer scored and analyzed by statistical programs found in the statistical Package for the social Sciences (S.P.S.S.) (Klecka, Nie, \& Hull, 1975; Nie, Hull, Jerisins, Steinbrenner, \& Bent, 1975). Two primary statistical methods, Chi-square and Factorial Analysis of Variance, were employed.

\section{Chi-square}

Chi-square may be used in testing bypotheses concerning the significance of the differences in the responses of two or more groups to a stimulus of one type or another (Downie \& Heath, 1970, p. 197). In this research, Chi-square was computed utilizing frequency of responses in contingency tables: as outlined in the S.P.S.S. Subprogram for Crosstabulation, Option One (Klecka \& others, 1975, pp. 70-79 Nie \& others; 1975, 218-248). Missing demographic and resolution data was not included in the statistical analyses.

The responses to the four items related to the 1985 Resolution by subjects, based on categories of demographic variables, are reported in frequencies and percentages. Chi-square was used to test the following statistical hypothesis:

1. There mill be no significant differences among 
nurses, baseủ on categories of seiected demographic variables, and the expressed degree of support for the 1985 Resolution and its related issues.

Crosstabulations on the four items related to the resolution were computed utilizing categories of the following variables: age; level of basic nursing preparation, hishest level of nursing education attained other than basic preparation; highest degree held outside of nursing; number of years of nursing experience; membership status in the American Nurses' Association; employuent status (employed versus unemployed); and employment setting (hospital versus other work settings).

Subjects were then divided into four groups, representing type of role organization, on the basis of the respondent's scores on the professional and bureaucratic scales. The possible range of scores on the bureaucratic scale is five to 30 . The subjects' scores on this scale ranged from 11 to 27 , with a median of 19.037 . The possible range of scores on the professional scale is eight to 40. The range of scores achieved in this study was 18 to 39 , with a median of 29.647 .

The scores on these two scales were divided at the mid-points on each of the two distributions, with subjects being classified as either "high" or "low" on each scale. The result was four categories of role organization: 1) high bureaucratic-high professional allegiances (HB-HP); 2) 
high bureaucratic-low professional allegiances (HB-LP); 3) low bureaucratic-bigh professional allegiances (LB-HP); and 4) low bureaucratic-low professional allegiances (LB-LP). Missing data were scored as an undecided response.

The responses to the four items related to the 1985 Resolution by the four groups are reported in frequencies and percentages and were statistically analyzed by use of Chi-square to test the following statistical hypothesis:

2. There will be no significant differences among the different role organization types adopted by nurses and the degree to which they express support for the four facets of the 1985 Resolution.

The sample population was then divided into two groups, based on respondents' total role deprivation score for the Corwin instrument. The possible range of scores for total role deprivation is zero to 56 . The subjects' scores ranged from one. to 36 , with a median of 14.036 . The distribution was divided at the mid-point, and each respondent was classified as either "high" or "low" in role deprivation. The same Chi-square technique was utilized to test the following statistical hypothesis:

3. There will be no significant differences among nurses with varying degrees of role deprivation and the degree to which they express support for the four facets of the 1985 Resolutions.

Factortal Analysis of Variance

Because prior research indicated that type of educational preparation and length of work experience may 
exert some influence on both type of role organization adopted by nurses and on the degree of role deprivation expressed by nurses, a further statistical analysis was conducted. Factorial Analysis of Variance was utilized to test the following six statistical hypotheses:

4. Tinere will be no significant differences among nurses with differing types of nursing education preparation and the degree to which they hold allegiance to the bureaucratic role.

5. There will be no significant differences among nurses with differing types of nursing education preparation and the degree to which they hold allegiance to the professional role.

6. There will be no significant differences among nurses with differing types of nursing education preparation and the degree of role deprivation they express.

7. There will be no significant differences among nurses with differing lengths of work experience and the degree to which they hold allegiance to the bureaucratic role.

8. There will be no significant differences among nurses with differing lengths of work experience and the degree to which they hold allegiance to the professional role.

9. There will be no significant differences among nurses with differing lengths of work experience and the degree of role deprivation they express.

Factorial ANOVA was utilized to determine what effect, if ang, the two independent variables of type of educational preparation and length of work experience have on the depencient variable of role conception scale score for each of the two allegiances, bureaucratic and professional, 
as mell as to examine any interaction of the two main effects. Further, Factorial ANOVA was used to determine main and interaction effects of the same two independent variables on the dependent variable of role deprivation.

"In factorial analysis of variance two or more independent variables vary independently or interact with each other to produce variation in a dependent variable" (Kerlinger, 1973, p. 245). It is a statistical method that analyzes the independent and interactive effects of two or more independent variables on a dependent variable (Kerlinger, 1973, p. 245). Thus, the effects of type of nursing education preparation and length of work experience were examined in relation to each of the dependent variables of bureaucratic scale score, professional scale score, and total role deprivation score. The analysis may serve as a basis for explaining differences to be found among groups of nurses in type of role organization adopted and the degree of role deprivation experienced by nurses.

Factorial ANOVA was conducted utilizing the classic experimental design with unequal cell frequencies in the S.P.S.S. computer program (Nie \& others, 1975, pp. 405-410). The default (or classic) option of the subprogram ANOVA was selected (Nie \& others, 1975, p. 415).

Two assumptions of the F-test have been violated in the analysis. This statistic assumes either an interval or ratio scale on the dependent variable measures and a normal 
distribution. In the study, the dependent measures are treated as if they are interval data in the statistical analysis. They are at least strongly ordinal. Violation of this assumption, however, has not been found to have a significant effect on the interpretation of the results. "From the evidence available, it would appear that the parametric tests...are reasonably robust in regard to this assumption; the rejection rate seems to be minimally affected by the use of ordinal data" (Marshall \& Hales, Note 2$, p. $17-6)$.

The assumption of normal distribution was also violated in the F-test of the bureaucratic role conception scale scores (kurtosis $=-0.472$, skewness $=-0.078$ ), the professional role conception scale scores (kurtosis = -0.188 , skewness $=-0.172$ ) and the total role deprivation scale scores (kurtosis $=0.292$, skewness $=0.684$ ). Again, this violation is not thought to significantly affect the results of the analysis of scores. Marshall and Hales (Note 2) summarized the findings of a number of studies which concluded the F-test to be nearly immune to violation of this assumption (p. 17-8).

\section{Additional Analysts}

Whenever an F-test revealed a significant finding, the Newman-Keuls Multiple Comparisons Test was conducted by use of the ANOVA subprogram One-Way in the S.P.S.S. package 
(Nie \& others, 1975, p. 427). This post-hoc comparisons procedure tests which of the group means differ significantly from one another (Huck, Cormier, \& Pounds, 1974, p. 67). The particular post-hoc comparisons test was selected because it is a moderately conservative statistic (Nie \& others, i975, p. 427 ).

When only contrast between two treatments...are of interest, the Scheffe and Tukey procedures....are overly conservative since they control [error experimentwise] for infinitely large sets of contrasts. The Newman-Keuls test controls [error rate experimentwise] yet provides greater power than other tests...because (a) it is based only on the set of possible contrasts between pairs of individual treatments and (b) successive tests involving smaller subsets of means are carried out as though only those treatments existed in the experiment. (Myers, 1972, p. 366)

When the situation exists in which there are unequal numbers being contrasted, as in this study, the Newman-Keuls becomes a slightly more conservative statistic (Walters, Note 3 ). The result is slightly greater risk of making a Type II Error, or accepting the statistical hypothesis when it should have been rejected. 


\section{CHAPTER IV}

\section{ANALYSIS AND DISCUSSION}

The study was conducted in the Spring of 1982 . Demographic characteristics of the subjects' were examined. Respondents' views towara the 1985 Resolution were examined in relation to demographic variables, the type of role organization adopted by nurses, and the degree of expressed role deprivation. The main and interaction effects of the independent variables of type of educational preparation and length of work experience on dependent variable of scale score for the three scales of Corwin's tool were examined and analyzed.

\section{DEMOGRAPHIC CHARACTERISTICS}

The majority of the 247 subjects mere female, over the age of 25 , and had been working 10 or more years in nursing. The respondents were more frequently educated in three year diploma schools, employed in hospitals, and reported they were not members of their professional organization, the American Nurses' Association. (see Table I I)

Males represented less than five per cent of the sample. This is typical of the profession where fewer than 
seven per cent of all nurses in the country are male (Educational Preparation for Nursing, 1976, p. 272).

Less than four per cent of the sample consisted of nurses under the age of 25. Nearly 40 per cent were 25 to 34 vears of age, 26.7 per cent were 35 to 44 , and 30.4 per cent were 45 and older. It is not known if the group under 25 years of age was under-represented in the study or if this age mix is representative of nurses in oregon (Oregon. State Board of Nursing, Note 4).

TABLE I I

DEMOGRAPHIC VARIABLES OF THE SAMPLE REPORTED IN FREQUENCIES AND

PERCENTAGE OF SUBJECTS

Sex:

Female

Male

Not Answered

Age:

Under 25 years of age 25 to 34 years of age

35 to 44 years of age

45 years of age and over Not Answered
236

11

0

95.5

4.5

0 
Demographic Variable

n per cent

Level of Basic Nursing Education:

$\begin{array}{lrr}\text { Associate Degree } & 68 & 27.5 \\ \text { Diploma } & 106 & 42.9 \\ \text { Baccalaureate Degree } & 72 & 29.1 \\ \text { Not Answered } & 1 & 0.4\end{array}$

Nursing Education beyond Basic Preparation:

Baccalaureate Degree

$\begin{array}{rc}55 & 22.3 \\ 15 & 6.1 \\ 0 & 0 \\ 172 & 69.6 \\ 5 & 2.0\end{array}$

Level of Non-Nursing Degrees Held:

Associate Degree
Bachelor's Degree
Master's Degree
Doctorate
None
Not Answered

Number of Years of Nursing Experience:

0 to 9 years

10 to 19 years

20 jears and over

Not Answered

Member of American Nurses' Association:

\section{Yes}

No

Not Answered

Type of Institution in which Employed:

Not currently employed

Hospital

$\begin{array}{rr}17 & 6.9 \\ 35 & 14.2 \\ 5 & 2.0 \\ 1 & 0.4 \\ 184 & 74.5 \\ 5 & 2\end{array}$

$106 \quad 42.9$

$75 \quad 30.4$

$66 \quad 26.7$

$0 \quad 0$

$\begin{array}{rl}73 & 29.6 \\ 174 & 70.4 \\ 0 & 0\end{array}$

$\begin{array}{ll}24 & 9.7\end{array}$

$127 \quad 51.4$ 
Doctor's office

Community bealth agency

Two year college

Diploma program

Four year college

Nursing home

Other

Not Answered

\section{TABLE II}


fields other than nursing. Nearly seven per cent of the sample indicated they had earned non-nursing associate degrees, 14.2 per cent held a bachelor's in a field other than nursing, two per cent reported having a non-nursing master's degree, and 0.4 per cent $(n=1)$ held a doctorate in a field other than nursing. The percentage of nurses in Oregon and in the nation who hold degrees outside of nursing is not known.

The subjects more frequently had professional nursing experience of nine years or less ( 42.9 per cent). Those with work experience of 10 to 19 years constituted 30.4 per cent of the sample, and those with 20 or more years of nursing experience represented 26.7 per cent of the sample.

Approximately 30 per cent indicated they were members of the American Nurses' Association (and thereby, members of the Oregon Nurses' Association). This is representative of the population of nurses in Oregon, where nearly 28 per cent of all nurses are members of their professional organization (Oregon Nurses' Association, Note 5).

Historically, nearly 30 per cent of the Registered Nurses in Oregon pere not actively employed (Oregon State Board of Nursing Annual Report, 1978). However, in the current sample less than 11 per cent of the subjects reported being currently unemployed. This recent trend towards a greater percentage of oregon nurses being employed may be due to the current economic recession in which more 
nurses need to work.

The majority of employed nurses in the study were currently working in hospitals ( 51.4 per cent). Nurses working in doctor' offices constituted 8.9 per cent of the sample. Slightly less than seven per cent of the respondents reported working in community health agencies. Nearly six per cent indicated they were employed in nursing homes, and two per cent of the subjects were employed in educational institutions $(0.8$ per cent in two year community colleges, 0.4 per cent in diploma nursing schools, and 0.8 per cent in four year colleges or universities). Approximately 15 per cent reported working in other types of facilities, including the following: public bealth programs; alcohol detoxification centers; health maintainence organizations, out-patient clinics; state health and planning programs; blood banks; medical products companies; research centers; insurance companies; retirement centers; dental offices; and dialysis clinics.

VIEWS TOWARD THE 1985 RESOLUTION

The $\nabla$ iews of 247 Oregon nurses toward the 1985 Resolution were examined. Comparisons of subjects' responses to the four facets of the resolution were made on the basis of different categories of demographic variables, type of nurse role organization, and degree of role 
deprivation.

\section{Nurses' Views}

Responses of nurses to each of the 1985 Resolution items were computer tabulated to answer the following question: What are the views of Oregon nurses regarding the issues surrounding the 1985 Resolution, including a professional/technical split in nursing practice, a baccalaureate requirement for professional licensure, a "grandfather clause" protecting currently licensed nurses, and the ladder mechanism for articulation among nursing educatiou pirugrams? (see Tabie III)

Results showed that the subjects were sharply divided in their degree of support for two levels of nursing practice and in their degree of support for the professional practice requirement of a bachelor's degree, reflecting a greater lack of consensus among nurses than has been previouslg reported. Consistent with earlier findings (Lee, 1979c), however, the majority of subjects supported the "grandfatber clause" and the ladder mechanism of articulation, associated with the resolution.

Nearly 49 per cent of those surveyed indicated they disagreed with the proposal for a professional/technical split while 48.9 per cent expressed support for the differentiation in levels of practice and licensure. The finding is substantially different from that reported by Lee 
TABLE I I I

SUMMARY OF SUBJECTS ' RESPONSES TO FOUR ITEMS

OF THE 1985 RESOLUTION

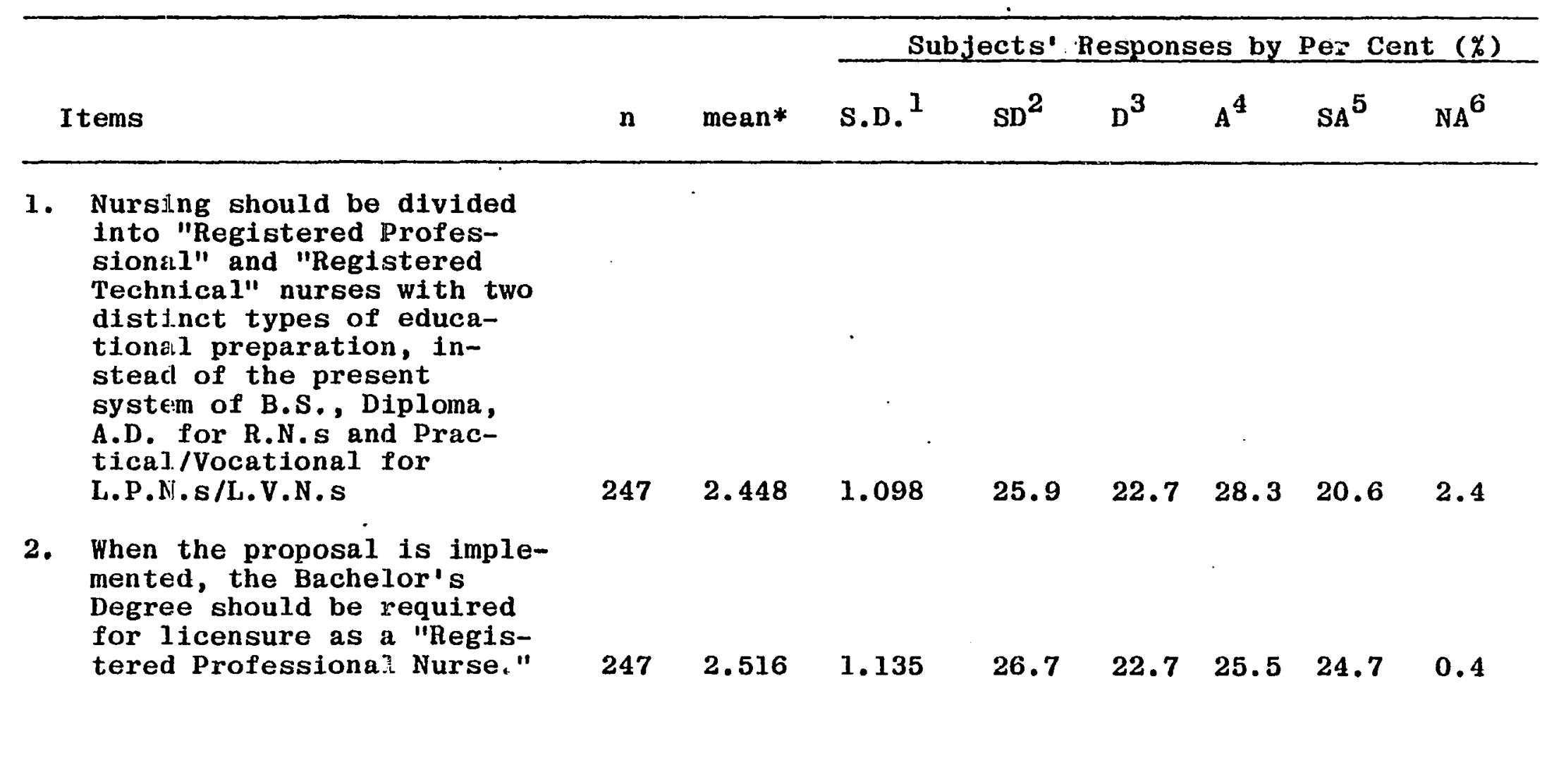


$\cdot$

Subjects' Response; by Per Cent (\%)

Items $\quad n \quad \operatorname{mean} * \quad S . D .1 \quad S D^{2} D^{3} A^{4} S^{5} \quad N^{6}$

3. Legislation implementing the proposal should not include a "grandfather clause" granting Registered Professional Status to all current R.N.S and Registered Technical Status to all current L.P.N.S/L.V.N.S

4. When the proposal is implemented, a "Registered Technical Nurse" should be allowed to enter any "Registered Professional Nurse" educational Program with full credit for previous nursing education.

*Range: $1=\mathrm{SD}-4=\mathrm{SA}$ with weighting reversed on Item 3

${ }_{\text {S.D. }}=$ Standard Deviation; ${ }^{2} \mathrm{SD}=$ Strongly Disagree; ${ }^{3} \mathrm{D}=$ Disagree; ${ }^{4} \mathrm{~A}=\mathrm{Agree}$;

$5_{\mathrm{SA}}=$ Strongly Agree; $6_{\mathrm{NA}}=$ No Answer 
(1979b) in which 72.7 per cent of the sample in that study expressed opposition to the proposal.

The subjects were also divided on the issue of entry level requirements for professional practice. Approximately 49 per cent of the sample expressed support for the bachelor's degree as the requirement for professional nursing practice while 50 per cent expressed their opposition. This finding is similar to that reported by Lee $(1979 b)$ in which 47.8 per cent of the respondents supported the bachelor's degree as the entry requirement for professional practice.

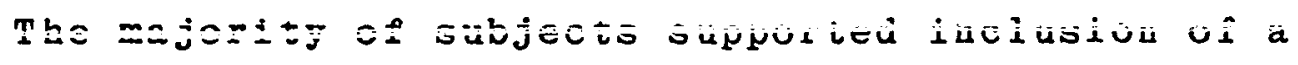
"grandfather clause" in the 1985 Resolution. The finding is consistent with that of Lee's (1979c) in which 80.8 per cent of his subjects expressed support for the clause.

The subjects expressed overwhelming support for the ladder mechanism of articulation between various types of nursing education programs. Approximately 89 per cent of the sample disagreed with the statement that a "grandfather clause" should not bo associated with implementation of the resolution. Lee (1979c) reported a similar finding in which 91.3 per cent of his subjects expressed approval of such a mechanism.

\section{Relationship of Demographic Variables}

The second research question, "What is the 
relationship between selected demographic variables and the degree of support or opposition expressed by nurses to the 1985 Resolution and its related issues?" was translated into the following statistical hypothesis:

1. There $\mathbf{w i l}$ be no significant differences among nurses, based on categories of selected demographic variables, and the expressed degree of support for the 1985 Resolution and its related issues.

Chi-square crosstabulatitons were utilized to analyze responses to the four items by categories of all demographic variables, excluding gender, in an effort to determine if significant differences existed in the responses of subjects, based on categories of demographic variables. A statistical hypothesis of no significant difference in responses to each item of the resolution was tested for each category of demographic variable, using the .01 alpha level. (see Tabie IV)

In the instances where more than 20 per cent of the valid cells had less than iive cases in the crosstabulations, categories of the independent variable (demographic) and/or categories of the dependent variable (response categories) were collapsed to reduce chances of a Type I Error. In those instances where maximum collapsing of the variable categories still produced the situation in which more than 20 per cent of the valid cell frequencies had less than an observed frequency of $n=5$, Yates' Correction was employed, using the procedure described by 
Marshall and Hales (Note 2, pp. 12-8-12-20), to minimize the risk of rejecting the statistical hypothesis when it should have been accepted (Type I Error). (see notation, Table IV)

TABLE IV

RESULTS OF MULTIPLE CHI-SQUARE TESTS ON RESPONSES

TO THE FOUR FACETS OF THE RESOLUTION BY CATEGORIES OF DEMOGRAPHIC VARIABLES

Relationship of Demographic

Variable by Resolution Item

Chi-square df Significance

AGE:

Professional/Technical Split
Bachelor's as Entry Requirement

Grandfather Clause

Ladder Mechanism

$\begin{array}{ccc}.715 & 2 & 0.30 \\ & & \\ .871 & 2 & 0.353 \\ 2.73 & 2 & 0.745 \\ 10.26 & 2 & 0.994\end{array}$

LERGTH OF WORK EXPERIENCE:

Professional/Technical Split ment

Grandfatber Clause

Ladder Mechanism

7.49193

$6 \quad 0.2777$

$\begin{array}{lll}8.93549 & 6 & 0.1772\end{array}$

$\begin{array}{lll}6.54 & 2 & 0.962\end{array}$

$\begin{array}{lll}4.94 & 2 & 0.915\end{array}$

A.N.A. MEMBERSHIP:

Professional/Technicl Split

Bachelor's as Entry Requirement

Grandfather Clause

Ladder Mechanism

\begin{tabular}{|c|c|c|}
\hline 3.31253 & 3 & 0.3459 \\
\hline $\begin{array}{l}4.10760 \\
1.89 \\
0.17154\end{array}$ & $\begin{array}{l}3 \\
1 \\
3\end{array}$ & $\begin{array}{l}0.2501 \\
0.80 * * * * \\
0.982\end{array}$ \\
\hline
\end{tabular}

EMPLOYMENT STATUS:

Professional/Technical Split

Bachelor's as Entry Requirement

Grandfather Clause

Ladder Mechanism

$\begin{array}{lll}3.27253 & 3 & 0.3515 \\ 2.91227 & 3 & 0.4053 \\ 0.219 & 1 & 0.30 * * * * \\ 3.67 & 1 & 0.945\end{array}$


Relationship of Demographic

Tariabie by Resolution Item

Chi-Square df Significance

EMPLOYING AGENCY:

Professional/Technical Splic

Bachelor's as Entry Requirement

Grandfather Clause

Ladder Mechanism

$\begin{array}{lll}5.27880 & 3 & 0.1461 \\ & & \\ 1.76041 & 3 & 0.6236 \\ 0.127 & 1 & 0.278 \\ 2.35 & 1 & 0.875\end{array}$

TYPE BASIC NURSING PREPARATION: Professional/Technical Split Bachelor's as Entry Requirement

Grandfather Clause

Ladder Mechanism

$\begin{array}{lll}56.68811 & 6 & 0.0000 * * * \\ 69.91817 & 6 & 0.0000 * * * \\ 19.97 & 2 & 0.0000 * * * \\ 5.08 & 2 & 0.921\end{array}$

NURSING EDUCATION BEYOND BASIC: Professional/Technical Split Bachelor's as Entry Requirement

Grandfather Clause

Ladder Mechanism

$\begin{array}{rll}36.03 & 2 & 0.999 * * * \\ 51.30 & 2 & 0.999 * * * \\ 18.27 & 2 & 0.999 * * * \\ 4.84 & 2 & 0.997 * *\end{array}$

OTHER DEGREES:

Professional/Technical Split

Bachelor's as Entry Requirement

Grandfather Clause

Ladder Mechanism

2.70

2

0.741

2.89

1.34

4.84

0.765

0.489

0.972

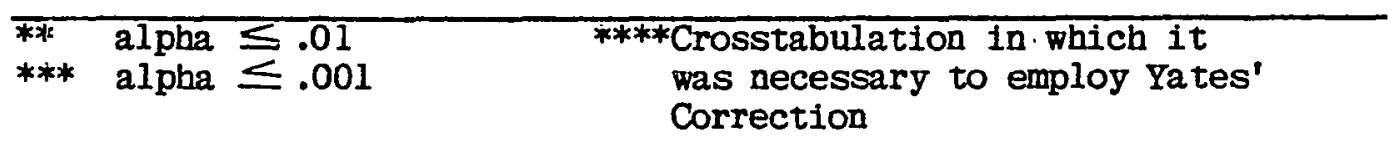

No statistically significant differences (.01 alpha level) were found among nurses in their degree of support for the four items of the resolution by: length of work 
experience; age; membership status in the American Nurses' Association; employment status; employing agency (hospital versus all other pork settings); or type of non-nursing degree beld. Not surprisingly, the type of basic nursing educational preparation and the level of nursing education achieved beyond the basic preparation were found to be significantly related to subjects' responses to the four facets of the 1985 Resolution.

subjects prepared in the three types of nursing education programs were found to differ significantly in their views on three of the four items of the resolution (.001 alpha level). Baccalaureate degree nurses more frequently supported the differentiation of two levels of nursing practice ( 84.3 per cent either agreed or strongly agreed) than did either diploma-prepared nurses (40.0 per cent agreed or strongly agreed) or associate degree nurses ( 30.8 per cent agreed or strongly agreed). (see Table V)

The result differs from findings reported by Lee (1979b) in which he stated 73 per cent of his baccalaureate nurse subjects and 20 per cent of the associate degree and diploma nurse subjects supported the two levels of nursing practice. Results of the current study strongly suggest that the type of basic nursing education experienced is a significant factor influencing nurses' views toward the two levels of nurse practice. 
TABLE $\nabla$

SUBJECTS' RESPONSES BY TYPE OF BASIC NURSING EDUCATION PREPARATION TO THE STATEMENT, "NURSING SHOULD

BE DIVIDED INTO REGISTERED PROFESSIONAL AND REGISTERED TECHNICAL NURSES..."

Type of Basic

$\mathrm{SD}$

D

A

SA

Nursing Education per cent per cent per cent per cent

\begin{tabular}{lcrrr}
\hline Associate Degree & 30.8 & 38.5 & 23.1 & 7.7 \\
Diploma & 36.2 & 23.8 & 25.7 & 14.3 \\
Bachelor's Degree & 7.1 & 8.6 & 40.0 & 44.3 \\
Chi-Square=56.68811 & df $=6$ & & alpha . .001 & \\
\hline
\end{tabular}

Subjects prepared in the three types of basic nursing education programs were found to differ significantly (alpha $.001)$ in their degree of support for the bachelor's degree as the entry requirement for professional nursing practice. The majority of baccalaureate degree nurses either agreed (30.6 per cent) or strongly agreed (55.6 per cent) that a bachelor's degree should be required. The majority of associate degree nurses did not support this requirement (68.6 per cent disagreed or strongly disgreed). Of these nurses, only 22.4 per cent agreed, and only nine per cent strongly agreed with this requirement. Similarly, the majority of diploma nurses expressed disagreement with this requi rement 
(61.3 per cent). Of the diploma nurse subjects, only 24.5 per cent agreed and 14.2 per cent strongly agreed with the requirement for a bachelor's degree. (see Table VI) These findings are similar to those reported by Lee (1979b) in which 86.7 per cent of the baccalaureate nurses, 45.5 per cent of the associate degree nurses, and 40.5 per cent of the diploma nurses in his study favored the baccalaureate degree requirement for entry into professional practice when the 1985 Resolution is adopted.

TABLE VI

SUBJECTS' RESPONSES BY TYPE OF BASIC NURSING EDUCATION PREPARATION TO THE STATEMENT, "...THE BACHELOR'S DEGREE SHOULD BE REQUIRED FOR..." A...PROFESSIONAL NURSE..."

\begin{tabular}{|c|c|c|c|c|}
\hline $\begin{array}{l}\text { Type of Basic } \\
\text { Nursing Education }\end{array}$ & $\begin{array}{c}\text { SD } \\
\text { per cent }\end{array}$ & $\begin{array}{c}D \\
\text { per cent }\end{array}$ & $\begin{array}{c}\text { A } \\
\text { per cent }\end{array}$ & $\begin{array}{c}\text { SA } \\
\text { per cent }\end{array}$ \\
\hline $\begin{array}{l}\text { Associate Degree } \\
\text { Diploma } \\
\text { Bachelor's Degree }\end{array}$ & $\begin{array}{r}32.8 \\
37.7 \\
4.2\end{array}$ & $\begin{array}{r}35.8 \\
23.6 \\
9.7\end{array}$ & $\begin{array}{l}22.4 \\
24.5 \\
30.6\end{array}$ & $\begin{array}{r}9.0 \\
14.2 \\
55.6\end{array}$ \\
\hline Chi-square $=69.91817$ & \multicolumn{2}{|c|}{$d f=6$} & alpha & .001 \\
\hline
\end{tabular}

Significant differences (alpha $\leq .001$ ) were found among subjects with the three types of nursing preparation in terms of their support for a "grandfather clause" 
Protecting currently licensed nurses when the resolution is implemented. Though the majority of respondents in each of the categories supported the clause, baccalaureate degree graduates did so less frequently. Approximately 97 per cent of the associate degree nurses and 94 per cent of the diploma nurses disagreed with the statement that there should not be such a protective clause in the resolution, whereas 76 per cent of the baccalaureate nurses so disagree. (see Table VII) These findings.are similar to those reported by Lee (1979c) in which 80.8 per cent of the subjects supported the clause. Lee (1979c) did find, however, that approximately 40 per cent of his baccalaureate nurse subjects opposed the clause, while less than 25 per cent of the baccalaureate nurses in the current study enpressed opposition.

\section{TABLE VII}

SUBJECTS' RESPONSES BY TYPE OF BASIC NURSING EDUCATION PREPARATION TO THE STATEMENT, "LEGISLÁTION IMPLEMENTING THE PROPOSAL SHOULD NOT INCLUDE A GRANDFATHER CLAUSE..."

Type of Basic

Nursing Education

Associate Degree

Diploma

Bachelor's Degree

Chi-square $=19.97$
3.1

5.7

23.6

$d f=2$ disagree

per cent 
Subjects with the three types of basic nursing education preparation were found not to differ significantly (alpha $\leq .01$ ) in their views of the ladder mechanism of articulation in nursing education. The vast majority of subjects in each category supported the implementation of this mechanism. (see Table VIII) This finding is consistent with views reported in the literature (Boyle, 1972; Ingles, 1971; Koffman \& Andruskiw, 1971; Lee, 1979c; Wood, 1973). There does appear to be a high degree of consensus ẵong nurses, regardless of nursing education preparation level, that the ladder mechanism is needed in the educational system.

\section{TABLE VIII}

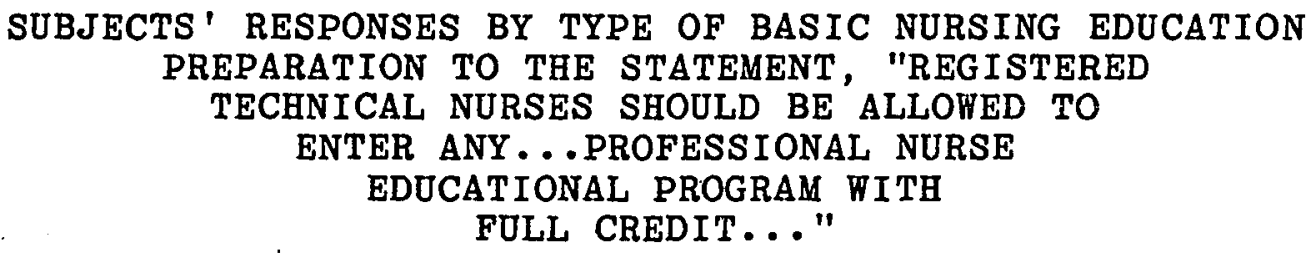

Type of Basic

Nursing Education disagree agree

per cent per cent

$\begin{array}{lrc}\text { Associate Degree } & 3.0 & 97.0 \\ \text { Diploma } & 9.6 & 90.4 \\ \text { Bachelor's Degree } & 13.9 & 86.1 \\ & & \\ \text { Chi-square=5.08 } & \text { df=2 } & \text { not significant }\end{array}$


Subjects were found to differ significantly on all four items of the resolution when advanced nursing education preparation was taken into account. While 69.6 per cent of the subjects had no nursing education preparation beyond their basic program, 22.3 per cent indicated they had returned to college to earn a bachelor's degree in nursing, and 6.1 percent of the subjects indicated their highest level of nursing education was that of a master's degree.

Nurses who had continued their education to earn either a baccalaureate or master's degree in nursing tended to support the professional/technical split in nursing more than did the nurse subjects reporting no nursing education preparation begond their basic program. of those subjects who reported no nursing education preparation beyond their basic program, only 39 per cent were in agreement with differentiation in levels of practice. In comparison, 79 per cent of those subjects who had returned to college to earn their bachelor's and nearly 93 per cent of those subjects who had earned a master's in nursing expressed support for the professional/technical split. (see Table IX)

The results may indicate that nurses who value eduation to the extent that they return to college to earn advanced degrees in nursing also ralue a professional/technical split in nursing. However, it may also indicate that such subjects tend to be supportive of the two levels because they, in essence, would not be 
injured by its implementation, whereas those subjects without a minimum of a bachelor's degree in nursing may perceive their careers would be adversely affected by implementation of the two levels.

\section{TABLE IX}

SUBJECTS' RESPONSES BY TYPE .OF NON-BASIC NURSING EDUCATION PREPARATION TO THE STATEMENT, "NURSING SHOULD

BE DIVIDED INTO REGISTERED PROFESSIONAL AND REGISTERED TECHNICAL NORSES..."

Nursing Education Beyond Basic Preparation

disagree

per cent agree

per cent

\begin{tabular}{|c|c|c|}
\hline $\begin{array}{l}\text { None beyond basic } \\
\text { Bachelor's Degree } \\
\text { Master's Degree }\end{array}$ & $\begin{array}{r}61.2 \\
21.1 \\
7.1\end{array}$ & \\
\hline Chi-squares $=36.03$ & $d f=2$ & alpha \\
\hline
\end{tabular}

Significant differences (alpha $\leq .001$ ) were also found among subjects in their degree of support for the bachelor's degree requirement for professional practice. Sixty-four per cent of the nurses with no preparation beyond their basic program disagreed with this requirement, while only 14.5 per cent of the subjects who had ultimately earned a bacheior's degree and 7.1 per cent of the master's degree-holders disagreed. Again, a vested interest in one's own level of nursing education may influence support for the 
bachelor's requirement. (see Table X)

TABLE $X$

SUBJECTS' RESPONSES BY TYPE OF NON-BASIC NURSING EDUCATION PREPARATION TO THE STATEMENT, "...THE BACHELOR'S

DEGREE SHOULD BE REQUIRED FOR...

A...PROFESSIONAL NURSE..."

\begin{tabular}{lcc}
\hline & disagree & agree \\
\hline $\begin{array}{l}\text { Nursing Education Beyond } \\
\text { Basic Preparation }\end{array}$ & per cent & per cent \\
$\ldots \ldots$ & 64 & 36 \\
\hline None beyond basic & 14.5 & 85.5 \\
Bachelor's Degree & 7.1 & 92.9 \\
Master's Degree & df=2 & alpha \\
Chi-square=5l.30 & $\ldots 01$ \\
$\ldots$
\end{tabular}

Femer nurses without preparation beyond their basic program ( 5.3 per cent) agreed that there should not be a "grandfather clause" associated with the resolution than among those with either a bachelor's (25.5 per cent) or a master's ( 14.3 per cent). Nurses without a minimum of a baccalaureate degree would be adversely affected in their careers without this protective clause. It is not surprising, therefore, to find they more frequently express support for the "grandfather clause" than do nurses with at least a bachelor's degree. (see Table XI) 
TABLE XI

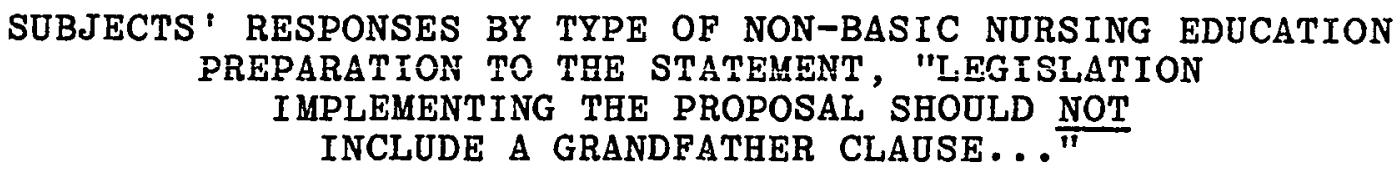

Nursing Education Beyond

Basic Preparation

agree

disagree

per cent

per cent

None beyond basic

Bachelor's Degree

Master's Degree

Chi-square $=18.27$
5.3

25.5

14.3

$d f=2$
94.7

74.5

85.5

The majority of subjects with and without advanced nursing educational preparation tended to support the ladder mechanism in nursing. However, as the level of nursing eduational preparation increased, the disagreement with this mechanism became stronger (alpha $\leq .01$ ). Approximately five per cant of the nurses without advanced preparation disagreed with the ladder concept, while nearly 15 per cent of the bachelor's degree-holders and 28.6 of the master's degree-holders disagreed. (see Table XII)

Whether a nurse has continued her/his formal nursing education or not appears to influence significantly the view 
toward each of the four facets of the 1985 Resolution. The results suggest that the more formal education experienced, the stronger the support for the professional/technical differentiation, the bachelor's degree requirement for professional practice, and the sironger the opposition to the "grandfather clause" and the ladder mechanism of articulation in nursing education.

\section{TABLE XII}

SUBJECTS' RESPONSES BY TYPE OF NON-BASIC NURSING EDUCATION PREPARATION TO THE STATEMENT, "REGISTERED TECHNICAL NURSES SHOULD BE ALLOWED TO ENTER ANY ... PROFESSIONAL NURSE EDUCATIONAL PROGRAM WITH FULL CREDIT..."

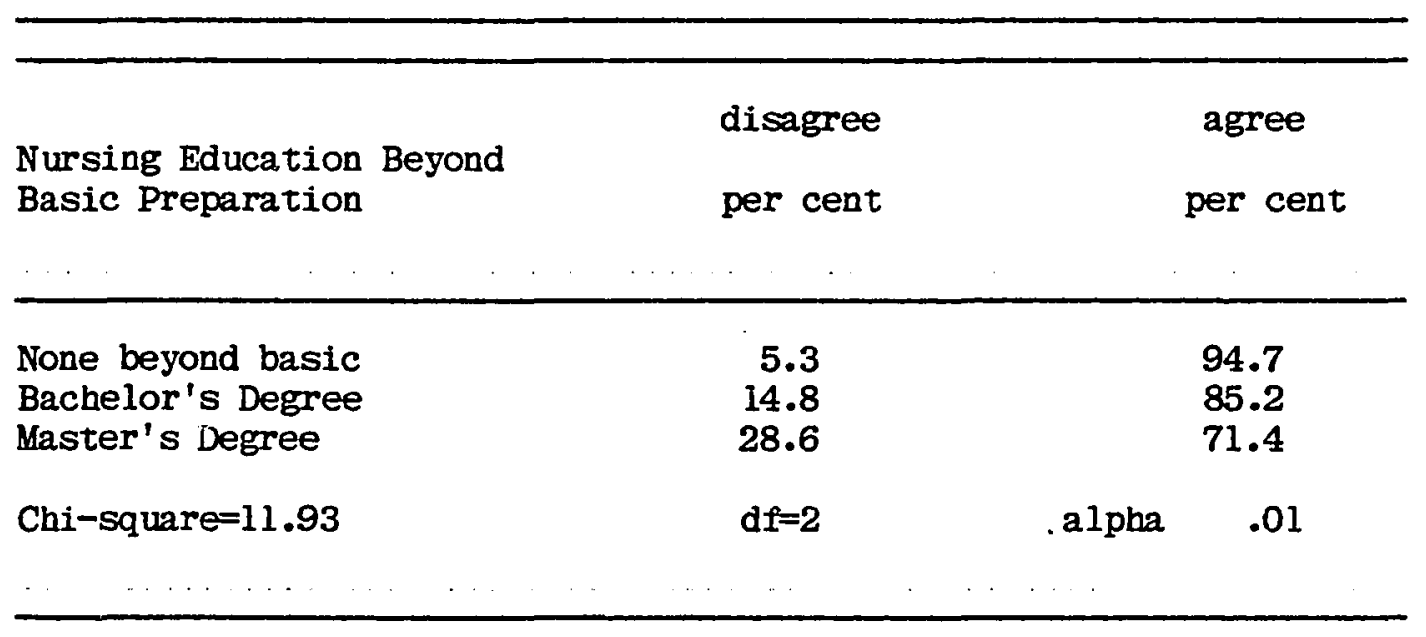

Results of multiple Chi-square tests on the degree of expressed support for the four items of the 1985 Resolution by categories of demographic variables suggest that type of basic nursing education preparation and the attainment of advanced nursing education are associated with nurses' 
degree of support for the resolution items. There does not appear to be ang such relationship between degree of support and the variables of age, length of work experience, membership status in the American Nurses' Association, employment status, type of employing agency, or type of non-nursing degree held.

\section{Relationship of Role Organization}

The third research question posed required exploration of the relationship between perceived role organization, using Corwin's model (1960), and nurses' views toward the 1985 Resolution and its related issues. The question was translated into the following statistical hypothesis:

2. There will be no significant differences among the different role organization types adopted by nurses and the degree to which they support the four facets of the 1985 Resolution.

Responses to the four resolution items were analyzed by role organization type using Chi-square crosstabulations. The research interest was to determine if nurses differed significantly in their responses to the four resolution items based on their role organization type. A statistical hypothesis of no significant differences in responses to each item of the resolution was tested for the four categories of role organization, using the .05 alpha level. (see Table XIII) 
TABLE XIII

RESULTS OF MULTIPLE CHI-SQUARE TESTS ON RESPONSES

TO THE FOUR FACETS OF THE RESOLUTION BY

TYPE OF ROLE ORGANIZATION

ADOPTED BY NURSES

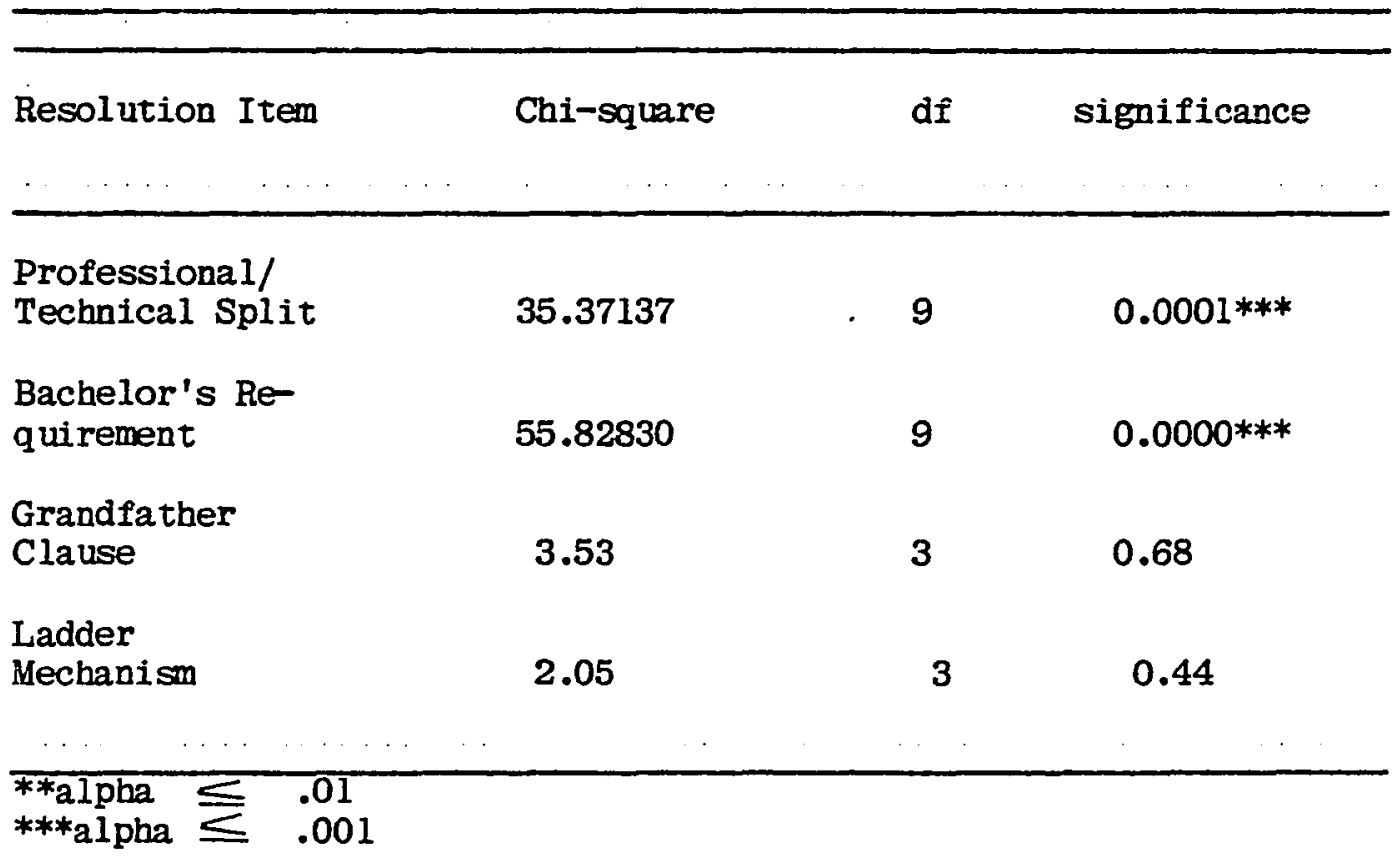

Nurses representing the four role organization types were found to differ significantly (alpha $\leq .001$ ) in their expressed degree of support for both the professional/technical split and the bachelor's degree requirement for entry into professional practice. No such significant differences were found among the four types of role organization adopted by nurses in relation to degree of support for the "grandfather clause" or the ladder mechanism.

Approximately 34 per cent of the subjects who adopted 
low bureaucratic and low professional allegiances (LB-LP) expressed agreement or strong agreement with the need for a professional/technical split in nursing practice, while 66 per cent of the subjects with this type of nurse role organization were in disagreement with the need for two levels of practice. Nurses who adopted high bureaucratic and low professional allegiances (HB-LP) expressed similar views, with 32 per cent in agreement and 68 per cent in disagreement.

Nurses who adopted low bureaucratic and high professional allegiances ( $L B-H P$ ) tended to agree with the proposal for a professional/technical split (approximately 70 per cent), while 30 per cent of the subjects with this type of role organization disagreed. Subjects who adopted high bureaucratic high professional allegiances (HB-HP) held similar views (63.3 per cent in agreement, 36.7 per cent in disagreement). (see Table XIV)

It is of interest that degree of allegiance to bureacratic principles (high or low) does not appear to be related to subjects' degree of support for the two levels of pracilice. However, it does appear that the degree of professional allegiance (high or low) is related to nurses' degree of support for the two levels of practice. (see Table $X V$ ) This finding is consistent with Corwin's conceptual framework (1960) of nurse role organization in which he theorized that nurses with a high degree of 
loyalty to professional principles were more committed to advancement of the profession than were nurses with less loyalty to professional values.

TABLE XIV

SUBJECTS' RESPONSES BY TYPE OF ROLE ORGANIZATION ADOPTED TO THE STATEMENT, "NURSING SHOULD

BE DIVIDED INTO REGISTERED PROFESSIONAL REGISTERED TECHNICAL NURSES..."



TABLE XV

PERCENTAGE OF AGREEMENT WITH TWO LEVELS OF NURSING BY DEGREE OF ROLE

ALLEG IANCES EXPRESSED

Allegiance by Role Oranization per cent

Low Bureaucratic:

$L B-L P$

$L B-I P P$
33.8

69.8
Allegiance by

Role Organization per cent

Low Professional:

$\begin{array}{ll}L B-L P & 33.8 \\ \text { HB-IP } & 32.0\end{array}$


(Continued)

TABLE XV

Allegiance by

Role Organization per cent

Role Organization per cent

High Bureaucratic:

$\mathrm{HB}-\mathrm{LP}$

$\mathrm{HB}-\mathrm{HP}$

32.0

63.3

High Professional:

L.B-HP

$\mathrm{HB}-\mathrm{HP}$

69.8

63.3

Approximately 33 percent of the subjects who adopted low bureaucratic and low professional allegiances agreed with the need for a requirement of a bachelor's degree for professional licensure, while 67 per cent of this group disagreed with the requirement. Similarly, nurses who adopted the high bureaucratic-low professional role organization tended to be in disagreement with the requirement (24 per cent expressed support and 76 per cent expressed diagreement).

Subjects who adopted the low bureaucratic-high professional type of role organization tended to agree with the bachelor's requirement (78.4 per cent), while 21.5 per cent of the group was in disagreement. A similar trend is noted among subjects who adopted the high bureaucratic-high professional role organization. (see Table XVI) 
TABLE XVI

SUBJECTS' RESPONSES BY TYPE OF ROLE ORGANIZATION

ADOPTED TO THE STATEMENT, "...THE BACHEIOR'S

DEGREE SHOULD BE REQUIRED FOR...A...

PROFESSIONAL NURSE..."

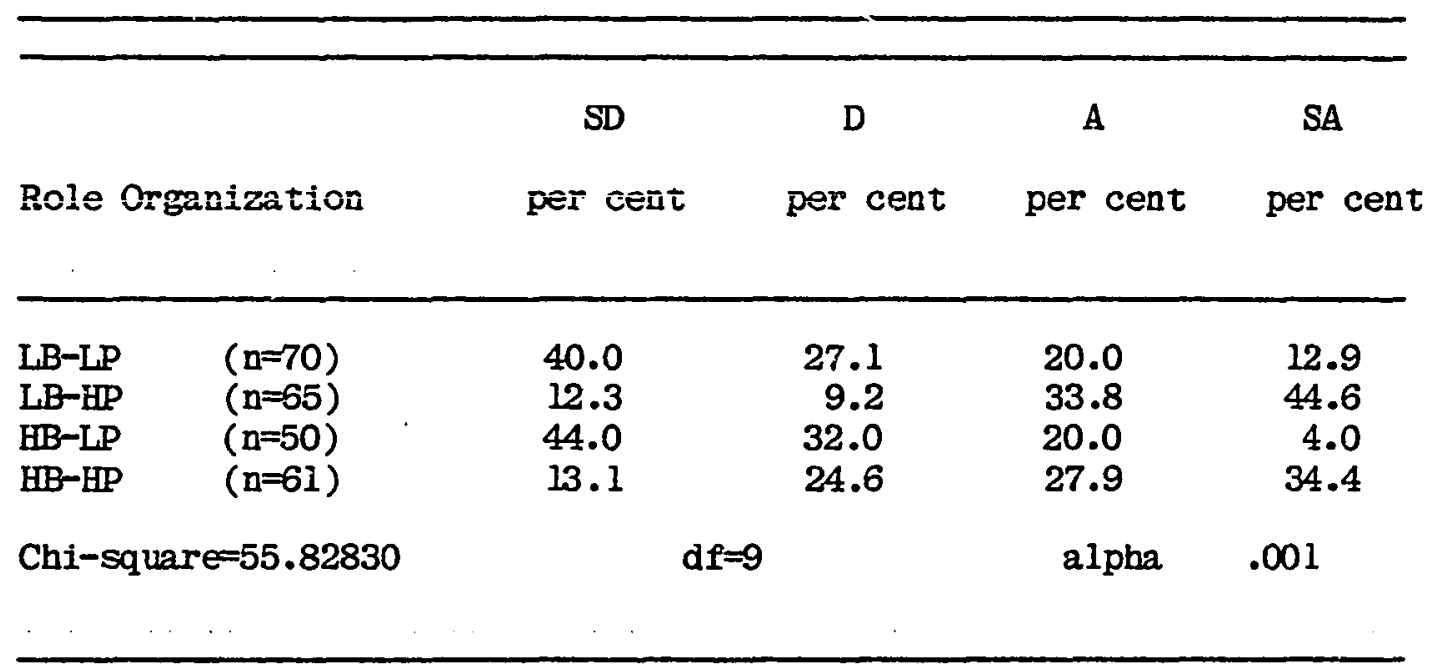

The liegree of allegiance to the bureaucratic role conception ( $h i g h$ or low), again, does not appear to be related to subjects' degree of support for the bachelor's degree requirement, while the degree of allegiance to the professional role conception (high or low) is related to subjects' degree of support for the requirement. Regardless of degree of expressed allegiance to the bureaucratic role conception, nurse subjects' with low professional allegiance appear to be less supportive of the bachelor's requirement than to those subjects with 2 higb degree of professional allegiance. (see Table XVII) 
TABLE XVII

PERCENTAGE OF AGREEMENT WITH BACHELOR'S REQUIREMENT

BY DEGREE OF ROLE AJLEGIANCES EXPRESSED

Allegiance by

Role Organization per cent

Allegiance by

Role Organization per cent

Low Bureaucratic:

LB-LP

LB-HP

32.9

78.4

Low Professional:

$L B-L P$

HB-LP

32.9

24.0

High Bureaucratic:

HB-LP

HB-HP

24.0

62.3

Low Professional:

LB-HP

$\mathrm{HB}-\mathrm{HP}$

78.4

62.3

Nurses representing all four types of role organization overwhelmingly supported both the "grandfather clause" and the ladder mechanism. The type of role organization adopted by nurses does not appear to be significantly related to their degree of support or opposition to these two items of the resolution.

In summary, the role organization adopted by subjects does appear to distinguish groups of nurses in their degree of support or opposition to such professional issues as levels of nursing practice and entry level requirements. Analysis of the data would seem to suggest that the degree of allegiance to professional ideals is more significant than allegiance to bureaucratic ideals in determining subjects' stances on at least these two issues of the 1985 Resolution. 
The resolution's requirement of two levels of practice and a bachelor's degree for entry to professional practice is aimed at advancement of the profession as a whole and improving the quality of nursing care delivered to health care clients. As expected, nurse subjects with a bigh degree of allegiance to professional ideals more frequently supported these two aspects of the resolution, regardless of degree of loyalty to bureaucratic principles, than did those subjects expressing a lesser degree of professional allegiance. These findings are consistent rith Corwin's conceptual framework (1960).

\section{Relationship of Role Deprivation}

The fourth research question was directed at an examination of the relationship between perceived role deprivation, using Corwin's model (1960), and nurses' views toward the resolution. Chi-square crosstabulations, with the significance level set at .05 , were employed to analyze the data in an effort to refute the following statistical hypothesis:

3. There will be no significant differences among nurses with varying degrees of role deprivation and the degree to which they support the four facets of the 1985 Resolution.

Comparisons of responses to each item were made between two groups of subjects. One group of subjects consisted of nurses with a lesser degree of expressed role deprivation (low role deprivation). The second group 
consisted of subjects with a greater degree of expressed role deprivation (high role deprivation). A statistical hypothesis of no significant difference in responses to each item of the resolution was tested, using the .05 alpha level, in an effort to determine the relationship between role deprivation and support for the resolution.

Analysis of the data revealed that the two groups of nurses did differ significantly in their views on two of the four items of the resolution, and the hypotiesis was rejected. (see Table XVIII)

TABLE XVIII

RESULTS OF MULTIPLE CHI-SQUARE TESTS ON RESPONSES

TO THE FOUR FACETS OF THE RESOLUTION BY

DEGREE OF ROLE DEPRIVATION EXPRESSED

\begin{tabular}{lccl}
\hline Resolution Item & Chi-square & df & significance \\
\hline $\begin{array}{l}\text { Professional/ } \\
\text { Technical Split }\end{array}$ & 13.22355 & 3 & $0.0042^{* *}$ \\
$\begin{array}{l}\text { Bachelor's Re- } \\
\text { quirement }\end{array}$ & 16.16636 & 3 & $0.0010^{* * *}$ \\
$\begin{array}{l}\text { Grandfather } \\
\text { Clause }\end{array}$ & .799 & 1 & 0.63 \\
$\begin{array}{l}\text { Ladder } \\
\text { iiecinanism }\end{array}$ & .080 & 1 & 0.22 \\
\hline
\end{tabular}

** $\quad$ alpha $\leq .01$

A high degree of role deprivation was found to be 
associated with stronger support expressed for the two levels of nursing practice. Of those subjects expressing a lesser degree of role deprivation, 41.3 per cent agreed with differentiating levels of practice, while nearly 59 per cent were in disagreement with this facet of the resolution. By comparison, nurses with a high degree of role deprivation tended to more írequently agree with the need for a professional/technical split (60.l per cent in agreement) and were less frequently in opposition (40 per cent in disagreement). (see Table XIX)

\section{TÁBLE XIX}

SUBJECTS' RESPONSES TO THE STATEMENT, "NORSING SHOULD BE DIVIDED INTO REGISTERED PROFESSIONAL AND REGISTERED TECHNICAL NURSES..." BY DEGREE OF ROLE

DEPRIVATION EXPRESSED

\begin{tabular}{|c|c|c|c|c|}
\hline Roì Deprivation & $\begin{array}{c}\mathrm{SD} \\
\text { per cent }\end{array}$ & $\begin{array}{c}D \\
\text { per cent }\end{array}$ & $\begin{array}{c}\text { A } \\
\text { per cent }\end{array}$ & $\begin{array}{c}\text { SA } \\
\text { per cent }\end{array}$ \\
\hline $\begin{array}{ll}\text { Lot } & (n=126) \\
\text { High } & (n=115)\end{array}$ & $\begin{array}{l}31.0 \\
21.7\end{array}$ & $\begin{array}{l}27.8 \\
18.3\end{array}$ & $\begin{array}{l}28.6 \\
29.6\end{array}$ & $\begin{array}{l}12.7 \\
30.5\end{array}$ \\
\hline Chi-square $=13.22355$ & $d f=$ & & alpha & .01 \\
\hline
\end{tabular}

The degree of role deprivation was also found to be significantly related to subjects' degree of support for the bachelor's requirement for entry into professional practice, 
nurses' expressing a bigh degree of role deprivation were more likely to support the requirement (59 per cent in agreement) than were nurses with a low degree of role deprivation ( 42.6 per cent expressing agreement). (see Table XX)

On the second two items, the degree of expressed role deprivation was not found to be associated with strength of support or opposition to the "grandfather clause" or the ladder mechanism. Subjects with low role deprivation disagreed with the statement that such a clause should not be implemented as part of the resolution (21.9) per cent in disagreement and 69.5 per cent strongly disagreed) as vehemently as did those subjects with a high degree of role deprivation (22.4 per cent disagreed, 65.5 per cent strongly disagreea). Similarly, both groups expressed strong support for the ladder mechanism, with 91.5 per cent of the subjects with low role deprivation expressing agreement (34.9 per cent agreed, 56.6 per cent strongly agreed), and 90.4 per cent of those nurses with bigh role deprivation in agreement with the need for this mechanism ( 31.3 agreed and 59.1 per cent strongly agreed). 
TABLE XX

SUBJECTS' RESDONSES TO THE STATEMENT, "...THE BACHELOR'S DEGREE SHOULD BE REQUIRED FOR ........ PROFESSIONAL NURSE..." BY DEGREE OF ROLE DEPRIVATION EXPRESSED

\begin{tabular}{|c|c|c|c|c|c|}
\hline Role & Jeprivation & $\begin{array}{c}\text { SD } \\
\text { per cent }\end{array}$ & $\begin{array}{c}D \\
\text { per cent }\end{array}$ & $\begin{array}{c}\text { A } \\
\text { per cent }\end{array}$ & $\begin{array}{c}\text { SA } \\
\text { per cen }\end{array}$ \\
\hline $\begin{array}{l}\text { Low } \\
\text { gigh }\end{array}$ & $\begin{array}{l}(n=129) \\
(n=117)\end{array}$ & $\begin{array}{l}28.7 \\
24.8\end{array}$ & $\begin{array}{l}28.7 \\
16.2\end{array}$ & $\begin{array}{l}27.9 \\
23.1\end{array}$ & $\begin{array}{l}14.7 \\
35.9\end{array}$ \\
\hline \multicolumn{2}{|c|}{ Chi-square $=16.16636$} & \multicolumn{2}{|c|}{$d f=3$} & alpha & .001 \\
\hline
\end{tabular}

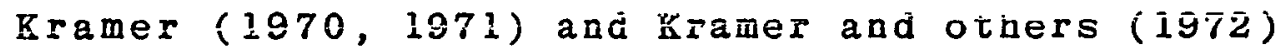
found high role deprivation to be associated with job dissatisfaction and the exodus from nursing. Corwin and others (1961) found it to be associated pith profassional disillusionment. Professional dissatisfaction and the desire for change (Corwin, 1960), associated with a high degree of role deprivation, may help to explain why subjects who are more role deprived tend to support implementation of the 1985 Resolution. Role deprivation, with its inherent tensions, may be a motivating force to seek change in the current state of nursing. Those nurses experiencing less role deprivation may be more interested in maintaining the status quo, since they experience less discrepancy in their professional and bureaucratic allegiances. 
Interactions of Factors Affecting Role Organization

The fifth research question sought to determine if the type of educational preparation and length of work experience affected the role organization of nurses. The main and interactive effects of educational pareparation and length of work experience on the destee of allegiance to the

- bureaucratic role, as measured by the bureaucratic role conception (BRC) scale developed by Corwin (1960), was analyzed by Factorial Analysis of Variance, in an attenpt to refute the following statistical hypotheses:

4. There will be no significant differences among nurses with differing types of nursing education preparation and the degree to which they hold allegiance to the bureaucratic role.

7. There will be no significant differences among nurses with differing lengths of work experience and the degree to which they hold allegiance to the buiceaucratic role.

The mean bureaucratic role coaception score calculated for all subjects in the study was 18.870 (possible scores on the scale range from six to 30 ), and the standard deviation was 3.542. The mode was 20.00 , and the median, 19.037 .

A $3 \times 3$ factorial design was used to examine the main and interaction effects of the two independent variables of education and length of work on the dependent variable, bureaucratic role conception score. An alpha level of .05 was selected. The Newman-Keuls Multiple Comparisons Test 
as used to compare groups when significant main effects were discovered.

The analysis resulted in a failure to reject ine null bypothesis of no significant differences among nurses with differing types of nursing education preparation. However, the null hypothesis of no significant differences among nurses with differing lengths of work experience was rejected (.001 alpha level). No interaction of the two main effects was detected. (see Table XXI)

The Newman-Keuls Test revealed each of the groups differed significantly from one another, when group means were compared. As length of work experienced increased, there was a significant increase in bureaucratic allegiance. (see Table XXI)

TABLE XXI

ANALYSIS OF VARIANCE FOR THE EFFECTS OF TYPE OF EDUCATION AND LENGTH OF WORK EXPERIENCE ON BUREAUCRATIC ALLEG IANCE

\begin{tabular}{|c|c|c|c|c|c|}
\hline Source of Variation & SS & df & $M S$ & F & $\begin{array}{l}\text { Sig. } \\
\text { of } F\end{array}$ \\
\hline $\begin{array}{l}\text { Main effects } \\
\text { Education } \\
\text { Work } \\
\text { 2-Way Interation }\end{array}$ & $\begin{array}{r}303.830 \\
42.025 \\
163.239 \\
54.792\end{array}$ & $\begin{array}{l}4 \\
2 \\
2 \\
4\end{array}$ & $\begin{array}{l}75.958 \\
21.012 \\
81.619 \\
13.698\end{array}$ & $\begin{array}{l}6.693 \\
1.852 \\
7.192 \\
1.207\end{array}$ & $\begin{array}{l}0.000 * * * \\
0.159 \\
0.001 * * * \\
0.308\end{array}$ \\
\hline $\begin{array}{l}\text { Explained } \\
\text { Residual }\end{array}$ & $\begin{array}{r}358.622 \\
2,689.508\end{array}$ & $\begin{array}{r}8 \\
237\end{array}$ & $\begin{array}{l}44.828 \\
11.348\end{array}$ & 3.95 & $0.000 * * *$ \\
\hline Total & $3,048.130$ & 245 & 12.441 & & \\
\hline
\end{tabular}


TABLE XXII

RESULTS OF THE NEMMAN-KEULS MULTIPLE COMPARISCNS TEST

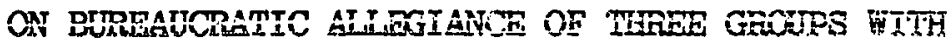
DIFFERIITG LENGIHS OF FORK EXPERIENCE

\begin{tabular}{lccc}
\hline Length of Work & $0-9$ years & $10-19$ years & 20+years \\
Number & 106 & 75 & 66 \\
Means & 17.8396 & 18.9333 & 20.4545 \\
& & & \\
\hline
\end{tabular}

The main and interactive effects of educational preparation and length of work expeisieace on the degree of allegiance to the professional role, as measured by the professional role conception (PRC) scale, developed by Corwin (1960), was also examined by Factorial Anaigsis of Variance to attempt to refute the folloming statistical hypotheses:

5. There will be no significant differences among nurses with differing types of nursing education preparation and the degree to which the g hold allegiance to the professinal role.

8. There will be no significant differences among nurses with differing lengths of work experience and the degree to which they hold allegiance to the professional role.

The mean professional role conception score calculated for all subjects in the study was 29.818 (possible scores on the scale range from eight to 40), and the standard deviation was 3.631 . The mode was 28.000 , and 
the median, 29.647 .

A 3 × 3 factorial design was used to examine the main and interaction effects on tae dependent variable of professional role conception score. An alpha level of .05 was selected.

In this analysis, the null hypothesis of no significant deifference among nurses on the professinal role conception mean scores, when compared by length of work experience, was accepted. However, type of educational preparation was found to be significantly associated with the degree of professional allegiance (alpha $\leq .001)$, àü the type of education and length of work experience, considered jointly, were found to be associated with the degree of professional allegiance (alpha $\leq .05$ ). (see Tahle XXITI)

\section{TABLE XXIII}

ANALYSIS OF VARIANCE FOR THE EFFECTS ON TYPE OF EDUCATION AND LENGTH OF WORK EXPERIENCE ON

PROFESSIONAL ALLEGIANCE

\begin{tabular}{lrrrrl}
\hline & & & & & \\
\hline Source of Variation & SS & df & MS & F & \multicolumn{1}{l}{$\begin{array}{l}\text { Sig. } \\
\text { of F }\end{array}$} \\
\hline Main effects & 218.692 & 4 & 54.673 & 4.539 & $0.001 * * *$ \\
$\quad$ Education & 201.750 & 2 & 100.875 & 8.374 & $0.000 * * *$ \\
$\quad$ Tork & 6.720 & 2 & 3.360 & 0.279 & 0.757 \\
2-Way Interation & 142.215 & 4 & 35.554 & 2.951 & $0.021 *$ \\
Explained & 360.907 & 8 & 45.113 & 3.745 & $0.000 * * *$ \\
Residual & $2,854.931$ & 237 & 12.046 & &
\end{tabular}


(Continued)

TABLE XXIII

\begin{tabular}{lcccccc}
\hline Source of Variation & SS & dî & MS & F & $\begin{array}{l}\text { Sig. } \\
\text { of F }\end{array}$ \\
\hline Total & $3,215.837$ & 245 & & \\
\hline
\end{tabular}

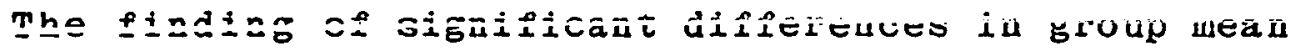
scores on the PRC scale in contrary to the results reported by Corwin in 1960. He found no such significant differences in group mean scores on the scale, when comparing diploma and baccalaureate students and diploma and baccalaureate graduates (1960, p. 239).

The inclusion of the third group of subjects, the associate degree-holders, in the current study may have contributed to the differing resulis. The difference in

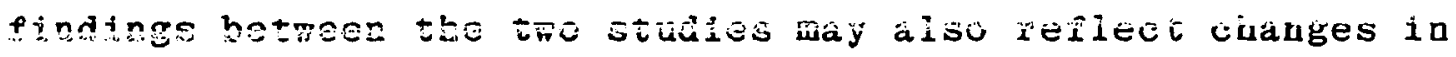
curriculum, in types of students admitted, graduate attitudes toward nursing, and practice during the 22 year interim of the two studies.

When the effects of the two-way interaction of type of education and length of work experience on group means for the professional role conception (PRC) score was graphed, a number of interesting finds emerged. (see Figure 1) The analysis suggests that there may be an erosion of allegiance to professional ideals in the two groups of subjects whose basic preparation was the associate degree and the baccalaureate degree as work experience increases.

Though initially baccalaureate nurses appear to hold 
a higher degree of allegiance to professional ideals than either diploma or associate degree nurses, a finding consistent with that of Brown and uthe:s (1974), the degree of allegiance appears to decline over time. A similar phenomenon is noted for the associate degree nurse subjects. Though there is a slight increase in allegiance to the professional ideals, when comparing nurses with 10 to 19 years of work experience to those with nine years or less, ultimately, there is a decline in allegiance, as length of work experience increases. This finding suggests that over time as loyalty to the bureaucracy increases among associate degree and baccalaureate nurses their professional allegiance is compromised.

Diploma nurse respondents with zero to nine years of work experience had the lowest mean score on the PRC scale, when compared to associate and baccalaurate degree nurses. However, professional allegiances of diploma nurses appear to approach those of baccalaureate nurses and surpass those of associate degree nurses over time, suggesting that for this group, length of work experience may be an important Pactor influencing the degree of professional allegiance.

In summary, findings suggest that bureaucratic allegiance is affected by the type of educational preparation nurses have, rather than by length of work experience or an interaction of type of education and length of work experience. In contrast, professional allegiance 
appears to be influenced by length of work experience and by an interaction of time on the job aud type of educational. preparation. Nurse role organization, in total, appears to be significantly related to the factors of type of educational preparation and length of professional work experience and their subsequent interactions.

\section{Interactions of Factors Affecting Role Deprivation}

The sixth research question led to an examination of the relationship of type of basic nursiug preparation and length of work experience on the degree of role deprivation expressed by nurses. Factorial Analysis of Variance mas employed to study the main and interactive effects of educational preparation and length of work experience on the dependent variable of total role deprivation (TRD) scale score. The statistic was used in an effort to reject the following statistical hypotheses:

6. There will be no significant differences among nurses with differing types of nursing education and the degree of role deprivation they express.

9. There will be no significant differences among nurses with differing lengths of work experience and the degree of role deprivation they express.

The mean total role deprivation score calculated for all subjects in the study was 15.405 (possibie scores on the scale range from zero to 56), and the standard deviation was 7.136. The mode was 13.000 , and the median, 14.036 .

A 3 x 3 factorial design was used to examine the main 


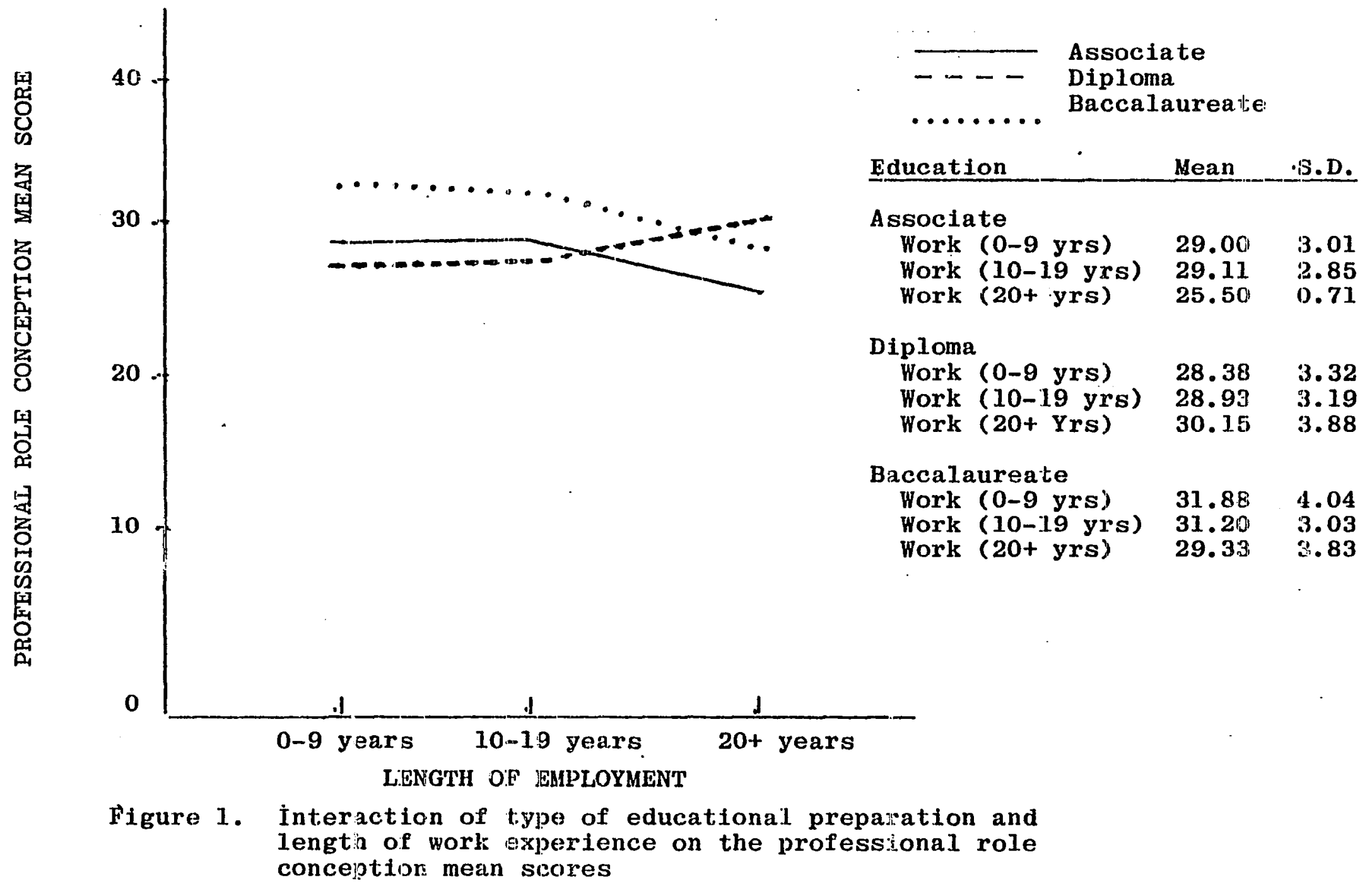


and interaction effects of the two independent variables of education and length of work experience on the defendent variable, TRD score. The data were analyzed and resulted in failure to reject either bypothesis at the alpha level selected $(\leq .05)$. Neither independent variable nor their interaction were found to be associated with the degree of expressed total role deprivation. (see Table XXIV).

\section{TABLE XXIV}

ANAIVSIS OF TAPIANCE POR TUE EPEECTS OT TYEE OF EDUCATION AND LENGTH OF WORK EXPERIENCE ON TOTAL ROLE DEPRIVATION

\begin{tabular}{|c|c|c|c|c|c|}
\hline Souce of Variation & $\mathbb{S S}$ & $d f$ & $\mathbf{M S}$ & $\mathbf{F}$ & $\begin{array}{l}\text { Sig. } \\
\text { of } \mathrm{F}\end{array}$ \\
\hline $\begin{array}{l}\text { Main effects } \\
\text { Education } \\
\text { Worix } \\
\text { 2-Way interaction }\end{array}$ & $\begin{array}{l}350.027 \\
255.511 \\
191.445 \\
325.214\end{array}$ & $\begin{array}{l}4 \\
2 \\
2 \\
4\end{array}$ & $\begin{array}{r}87.507 \\
127.755 \\
95.722 \\
81.304\end{array}$ & $\begin{array}{l}1.761 \\
2.571 \\
1.926 \\
1.636\end{array}$ & $\begin{array}{l}0.137 \\
0.079 \\
0.148 \\
0.166\end{array}$ \\
\hline $\begin{array}{l}\text { Explained } \\
\text { Residual }\end{array}$ & $\begin{array}{r}675.2 A 1 \\
11,778.096\end{array}$ & $\begin{array}{r}8 \\
237\end{array}$ & $\begin{array}{l}84.405 \\
49.697\end{array}$ & 1.698 & 0.099 \\
\hline Total & $1 \overline{2}, 453.337$ & 245 & 50.830 & & \\
\hline$\ldots \ldots$ & . & & & $:$ & \\
\hline
\end{tabular}

The degree of expressed total role deprivation does not appear to differ among groups of nurses, when compared by types of educational preparation and by length of mork experience. This is in apparent contrast to earlier studies (Kramer, 1969; Miller, 1967; Tetreault, 1976) in which some evidence was found to suggest that the sense of role 
deprivation may increase with time in the job. $\therefore$ 


\section{CHAPTER V}

SUMMARY, CONCLUSIONS, AND RECOMMENDATIONS

\section{SUMMARY}

The purpose of the study was three-fold: (1) to explore the views of Gregon nurses toward the four facets of the controversial 1985 Resolution to change the education and practice requirements of nurses in the future; (2) to earmine the efficacy of the model of role organization and role deprivation, developed by Cormin (1950), in distinguishing and explaining nurses' views on the four issues of the 1985 Resolution; and (3) to examine the effects of the type of nursing educational preparation and the length of professional work experience on nurses' expressed alieglance to the bureaucratic and to the professional roles and on the degree of expressed role

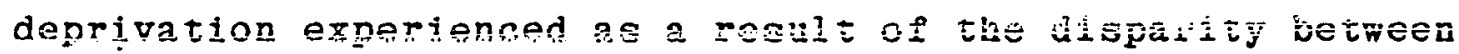
ideal role conceptions and the practice realities in nursing .

The data-gathering tool was a mailed questionnaire containing three instruments: an eight item demographic sheet; a four item instrument, "Views Toward the 1985 Resolution", containing declatatye statements ou four issues of the resolution with a Likert-type response scale; 
and a 14 item instrument, "Role Organization" (Corwin, 1960), also containing declaratige statements witu Likert-type response options. The response rate to the mailed questionaaire was 84 per cent.

The sample consisted primarily of females, the majority of whom were employed in hospitals and were not members of their professional organization, the American Nurses' Association. Less than four per cent of the subjects were under the age of 25 , with the remainder falling within the ages of 25-34 (38 per cent), 35-44 (27 per cent), and 45 and over ( 30 per cent).

Diverse educational preparation was apparent among the subjects. Among respondents, 43 per cent had received their basic nursing preparation in diploma schools, 28 per cent in associate degree nursing programs, and 29 per cent

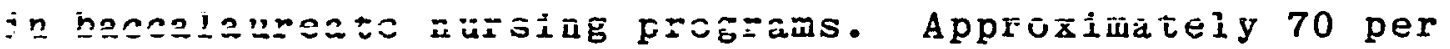
cent of the sample had no preparation in nursing beyond their basic educapional program. Approximately 24 per cent of the respondents reported holding non-nursing academic degrees.

The length of professional work experience varied considerably. Nearly 43 per cent of the subjects had practiced less than 10 years. The remainder bad practiced either 10 to 19 Jears (30 per cent) or more than 19 years (27 per cent).

Oregon nurses were divided on two issues associated 
with the 1985 Resolution. One-half of the respondents expressed varying degrees of support for a professional/techüical differentiation in levels of practice and licensure, and one-half expressed opposition to this proposal. The same lack of consensus occurred on the question of the bachelor's requirement for entry into professional practice, with the subjects nearly equally divided in their responses on the question. The overwhelming majority indicated a "grandfather clause" should be associated with the 1985 Resolution. The vast majority also indicated that as an aspect of the resolution they supported the development of a career ladder mechanism of articulation among various types of nursing programs.

The relationship of demographic variables to subjects' views of the four facets of the 1985 Resolution


three of the four items of the resolution, significant differences were found when comparing groups of nurses with differing types of basic nursing education preparation.

Baccalaureate-prepared nurses more frequently supported the two levels of nursing practice than did either associate degree or diploma nurses, and this group advocated the bachelor's requirement more strongly than did either associate degree or diploma nurses. The groups also differed significantly in their degree of support for the "grandfather clause". Nearly 97 per cent of the associate 
degree and 94 per cent of the diploma nurses expressed support for this protective clause, while only 76 per cent of the baccaiaureate degree nurses did so. Nurses varying types of basic preparation in nursing were not found to differ significantly in their support for a ladder mechanism.

Subjects differed significantly on all four items of the resolution when advanced nursing educational preparation was taken into account. As the level of preparation obtained beyond the basic nursing education program increased, the degree of support for the professional/technical split in practice and the bachelor's requirement for entry into professional practice increased. As the level of nursing educational preparation increased, the degree of support for the "grandfather clause" and the

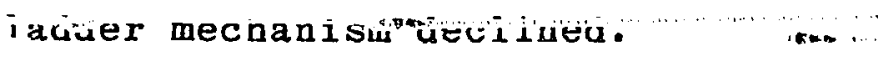

Chi-square crosstabulations were used to compare subjects in their degree of support for the four items of the resolution on the basis of type of role organization adopted. Nurses with high bureaucratic-high professional allegiances and nurses with iow bureaucratic-bigh professional allegiances were significantly more supportive of both the professional/technical split and the bachelor's requirement than were nurses with either bigh bureacratic-low professional or low bureaucratic-low professional allegiances. The four categories of nurses by 
type of role organization did not differ significantly in tneir degree of support for the "grandfather clause" or the ladier mechanisin.

The effects of role deprivation on subjects' views toward the resolution were examined by the same Chi-square crosstabulation procedures. Nurses categorized as high in expressed role deprivation demonstrated significantly greater support for the professional/technical split and the bachelor's requirement than did nurses categorized as low in expressed role deprivation. The two groups did not differ significantly in their degree of support for the protective clause or the ladder mechanism of articulation.

The main and interaction effects of the independent variables of type of educational preparation and length of work experience on the three dependent variables of scale =000 Factorial Analysis of Variance procedures. No interaction of the two main effects was found in analyzing mean scores on the bureaucratic role conception (BRC) scale or on the total role deprivation (TRD) scale.

The independent variable of length of work experience was found to be associated with the degree of bureaucratic allegiance. Bureacratic allegiance was found to increase significantly as length of work experience increased.

Examination of the effects of the too independent variables on the dependent variable of professional 
allegiance revealed a significant interaction. As length of work experience increased for associate degree and baccalaureate nurses, prosessional allegiance declined. Allegiance to the professional role was found to increase with the length of work experience for diploma nurse subjects.

\section{CONCLUSIONS}

Prior to the study, there had been little systematic research of the views of nurses toward the 1985 Resolution reported in the literature. The extent of support or opposition to the resolution among Oregon nurses was not known. One purpose of the study was to explore these views of a sample of Oregon nurses. The use of the random sample technique in the study and achievement of a respouse rate of 84 per cent suggests the findings are an accurate

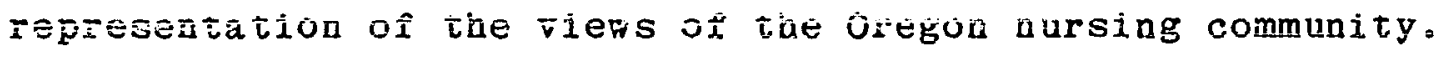

The results suggest that oregon nurses are equaliy divided in their views toward the two levels of practice and toward the bachelor's requirement for entry into professional practice. This lack of consensus is so substantial that it may be expscted to delay and/or make implementation a more arduous process.

There exists a large contingency of nurses on both sides of the issue with considerable potential for 
influencing the political arena of the state legislature, where the proposal for enactment of the resolution will be examined and considered for legislative action. If both contingencies rally large numbers of nurses and present their cases equally well, it is very likely that state legislators will decline to enact the resolution into law. Thus, it would appear to be unwise for supporters of the resolution to bring the issue to the state legislature for enactment at this time. When greater consensus exists among nurses or when supporters believe that the arguments for the resolution are sufficiently strong to outweigh any opposition (which currently is strong in Oregon), supporters should then seek to convince state legislators of its necessity.

Supporters of the resolution, such as the American Nurses' Association and the Oregon Nurses' Association, should find the study results encouraging. Opposition to the resolution in Oregon is not as strong as has been previously reported in the literature (Lee, 1979a, b, c, d). The findings suggest that a large reservoir of support exists that could be marshalled and organized to promote individual and collective actions leading to implementation of the resolution.

There is strong agreement among Oregon nurses that a protective "grandfather clause" should be an aspect of any legislation to implement the resolution. The evidence of 
overwhelming support for such a protection would seem to indicate that failure to include protective language in pioposed legislation could seriously erode support for the resolution and generate even more formidable opposition. Individuai nurses and professional groups who are opposed to inclusion of the "graidiather ciause" should consider this finding carefully. Opposition to the protective clause may doom all implementation efforts to ultimate failure.

The findings indicate that Oregon nurses overwhelmingly endorse a system of articulation among nursing education programs which makes a career ladder possible in nursing. If such a mechanism was available statewide to Oregon nurses, it is possible that greater numbers of nurses would return to the educational. system to earn baccalaureate degrees, thus moving the profession closer to its expressed goal of increasing the number of nurses prepared to practice at the baccalaureate level. Such mechanism in place may serve to diminish opposition to the resolution in the future. As more nurses earn the baccalaureate degree, the greater are the numbers likely to suppoit the resolution. It rould provide an option, not now readily available, to non-baccalaureate nurses who view the resolution as adversely affecting their own career advancement.

An effort was made to determine if relationships existed between certain of the demographic variables and 
nurses' views toward each of the four items of the resolution. Based on the study results, no significant relationships were found between nurses' degree of support for the four facets of the resolution and the following demographic characteristics: age; length of work experience; mambership status in American Nurses' Association; employment status; type of employing agency; and level of non-nursing higher education achieved.

The investigation did, however, reveal that the type of basic nursing education completed and the level of ẩvanuced nursing education achieved were associated with the degree of exprassed support for the resolution items: The findings suggest that nurses' values and beliefs; at least as they are reflected in their stances on various aspects of the resolution, differ, depending on their basic preparation j.n nursing and the levei of nursing education obtained. If support for the resolution is considered reflective of allegiance to professional ideals and advancement of the profession, then the study results support those of earlier investigations (Brown \& others, 1974) in which it was found that professional attitudes increase with length of time in nursing education programs. The findings also suggest the type of nursing education program is a significant factor in relation to nurses: views of the resolution.

These results are of importance to nursing education faculties and administrators and professional associations 
who are currently questioning how and where in the lives of nurses can attitudes and values be most significantly intiluenced. The academic arena would seem to be a crucial place in which to identify and instill those attitudes, values, and beliefs which support the kind of professional advancement and improved practice the 1985 Resolution is said to represent. Education, both formal and informal, basic and continuing education, would seem to be criticaíy important elements in any strategy to promote acceptance of the resolution.

A second purpose of the investigation was to examine the efficacy of Corwin's model of role organization and role deprivation in distinguishing and explaining nurses' views toward the resolution. In order to test this conceptual framework, it was predicted that the type of role organization and degree of role deprivation, representing various configurations of attitudes, values, and beliefs, woula be found to be associated with the views nurses adopted toward the resolution.

The development of role theory and the testing of associated hypotheses are of importance to' the profession, because occupational role perceptions generate the attitudes and beliefs which guide occupational behaviors. How one perceives ara saacs the role will determine the set of behaviors which will constitute the practice of nursing. If the form and quality of nursing practice is to be advanced 
it is imperative to understand what motivates and influences nursing behapiors through thếsy bullding and testing. When more is understood about what factors influence the assumption of the professional role, in terms of attitudes, values, and beliefs, those factors can be eliminated, modified, or strengthened.

The model pas iound to have efficacy in distinguishing nurses in their view toward two major issues of the resolution: the two levels of practice; and the bachelor's requirement. It was not found to be useful in differentiating nurses' views toward the "grandfather clause" or the ladder mechanism of articulation.

Assuming that implementation of the resolution represents a substantial advancement for the profession of nursing, in terms of improving academic preparation and practice standards, then che findings would appear to be consistent with conceptual model. It has been previously hypothesized that role organization and role deprivation are factors in nurses' allegiance to the profession, as a whole (Corwin, 1960; Kramer, 1968b, 1970). Here it was found that nurses with a high degree of professionai aliegiance, as measured by the professional role conception (PRC) score, regardless of role configuration, expressed significantly greater support for the professional/technjcal split in practice and for the bachelor's requirement for professional practice. 
Further, role deprivation has been previously hrpothasized to be a motive porce is seeking change in nursing. The study results mould appear to support this hypothesis. Nurses who supported the two levels of practice and the bachelor's requirement had significantly greater degrees of role deprivation than did non-supporters, and the implementation of the resolution represents one of the most profound changes in education and prantise in tho bistory of nursing.

The third purpose of the study was to examine the effects of type of nursing education preparation and length of work experience on nurses' allegiance to professional ideals, as measured by the professional role conception (PRC) score, allegiance to bureaucratic ideals, as measured by the bureaucratic role conception (BRC) score, and on nurses' degree of role deprivation; as measured by the total role deprivation (TRD) score. As a further contribution to the study of nursing role theory, these factors were examined to determine what influence they may exert on the emergence of occupational role and in sustaining or altering role conceptions during professioúal practice.

When more is buown about what factors intluence role conception, it may then be possible to track and modify their effects in both educational and practice settings. This may lead to development of a more consistent role configuration among nurses and contribute to greater 
consistency in behavior constituting the practice of nursing and to consensus on the present and future course of nursing practice.

Consistent with other findings (Corwin, 1960), length of work experience was found to be a factor in degree of bureaucratic allegiance. The ionger a nurse practices, the greater loyalty expressed to bureaucratic ideals. This would appear to be a predictable post-graduate process of adjustment, one which allows the nurse to survive in and feel loyalty to the work system. Based on the findings, type of educational preparation appears to exert no influence on the degree of bureaucratic allegiance. Neither do these two factors interact to exert an effect on the degree of expressed bureaucratic allegiance.

The degree of professional allegiance was found to be associated with the type of educational preparation and with an interaction of type of educational preparation and length of work experience. Nurses prepared in academic institutions (baccalaureate and associate degree) appear to initially express greater professional allegiance than do diploma nurses: Hopeqer, Over tia baccalaureate and associate degree nurses' allegiance appears to decline, while that of diploma nurses increases.

It is not known if the severity of the schism between academic institutions and work settings explains this decline in professional ideals. Further; the variables 
operating in the work enviornment which over time appear to promote declining professional allegiance among associate degree and bachelor's degree nurses, while enhancing those among diploma nurses, are incompletely identified and poorly understood.

The degree of role deprivation was not found to be associated with type of educational preparation or length of work experience or an interaction of these variables. The findings are contrary to earlier works (Kramer, 1969; Miller, 1967; Tetreault, 1976). It may be that factors operating in the educational and work setting, which promote role deprivation, have been modified in the years between the present and earlier studies. What variables are associated with role deprivation remain to be identified.

Research identifying the variables operating in both

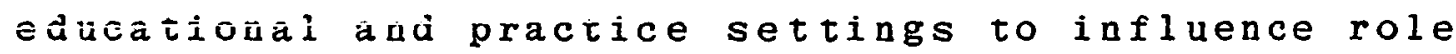
allegiances and role ceprivation is in its initial stages. The association of two factors with bureacratic and professional allegiances and with role deprivation has been established in the study. Identification of other variables and their interactions which operate to increase or decrease role allegiances and role deprivation await further research.

There exists a paucity of nursing role theory development and testing. The role organization model has been found to be useful in distinguishing particular 
behaviors, attitudes, valủess, âû̉ beliếs ồ nurses. İ was not found to be fully satisfactory in tenatively explaining nurses: stances on ail professional issues of the 1985 Resolution. However, the study results can serve as a contribution to further development of the particular theoretical framework or serve as part of the baseline data for new theory development.

The type of role organization and degree of role deprivation appear to be useful tools in predicting nurses' views towards aspects of the 1985 Resolution. The type of basic educational preparation and level of nursing education achieved also appear to he nseful predictors of resolution views. Of these four variables found to be significantly associated with viems toward the resolution, the level of nursing education achieved appears to be the most sensitive predictor of viéws towards all four issues of the resolution.

\section{RECOMMENDATIONS}

With a considerable lack of consensus among nurses, implementation of the 1985 Resolution in Oregon is likely to be a painfully slow process. Formidable support appears to exist for both sides of the resolution issue which could lead to continuous delays in enactment. As a result of this study, it is recommended that any proposed legislation to 
enact the resolution include the protective "grandfather clause", unless the profession is prepared to suffer further erosion of support for the resolution.

It is also recommended that the various professional groups, including the professional association, nurse educators, the regulatorg hody, and interested groups of nurses at-large, work to lmplement a career ladder in nursing education. A ladder mechanism of articulation among the various nursing education programs available tbroughout the state could serve several purposes: (1) It can serve as a mechanism to increase the number of baccalaureate prepared nurses in Oregon and increase the educational opportunities for nurses at all levels; and (2) If it was in place prior to implementation of the resolution, less opposition might be expressed. A mechanism for career advancement would be available to nurses who are concerned the resolution may penalize them for their lack of a bachelor's degree; and (3) Such a mechanism would likely provide greacer numbers of baccalaureate nurses. This would increase the pool of nurses supportive of the change in practice and education.

It is recommended that the professional association continue to sponsor educational for ums throughout the state which provide nurses with an opportunity to learn more about the esolution and its benefits. Continuing education workshops should be offered which speak to the future 
practice demands for nurses and the current status of nursing in health care and serve to enlighten nurses about future trends which support the case for the resolution. Such continuing education programs could be offered in academic settings and carry elective nursing credits toward a bachelor's degree in nursing.

The benefits of providing educational forums in workshop or course format are several, not the least of which may be a greater awareness and understanding of the aims of the resolution among nurses throughout the state. Secondly, the study results indicate that the more education a nurse achieves, the greater tíe likelihood he/she will support the resolution. Thus, providing formal continuing education programs may, by themselves, advance the cause of the resolution.

Considerable effort shouid be invested in identifying nurses at the iocal level, both within and outside of the professional association, who support the resolution and who can be organized to garner support for the resolution,

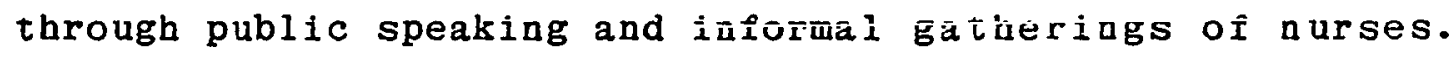
A large contingency of supporters does appear to exist who currently lack a network of communication regarding the resolution implementation efforts and a formal network to organize their efforts and utilize their persuasive abilities.

Professional associations should consider convening 
task forces of nurse educators, nurses at-iarge, and hospital administrators to study the various issues related to implementation of the resolution, to anticipate problems its implementation may cause, and to plan strategies to implement the resolution in educational and in practice settings. These individuals, in turn, may be instrumental in their own work settings in consciousuess-raising among nurses and non-nurses, alike, regarding the resolution, as well as in nurturing additional support for its implementation.

Employers of nurses across the state should be encouraged through informal and formal mechanisms, such as collective bargaining and institutional nursing practice committees, to provide salaries commensurate with educational preparation. Conjointly, position descriptions reflecting differentiation in levels of practice should be developed. A higher saiary for a higher level of educational preparation should be accompanied by an expectation of a different level of pratice and responsibility.

If such differentiation in salary and practice was more widespread, there might be greater acceptance of the resolution, even prior to enactment. Differentiation in salary and practice could also serve as an incentive to present and future nurises to obtain advanced levels of preparation in nursing. This in itself could indirectly 
advance the cause of the resolution, since nurses who have obtained advanced levels of nursing education tend to support the resolution.

There should be continued efforts to test and refine the theory of nurse role organization. Other variables could be examined, using type of role organization and/or degree of role deprivation, to determine if relationships exist. Type of role organization and degree of role deprivation, in effect, are maasures of the intensity of allegiances to ideals and the conflict between ideals and practice realities. They should, therefore, be related to views toward other professional issues, such as the following: expressed support or opposition to professional credentialing mechanisms now being advocated by such organizations as the American Nurses' Association; or expressed support or opposition to the prospect of institutional licensure advocated by certain employers of nurses. The variables of role organization and deprivation could be expected to be related to the degree of support nurses express for expanded clinical privileges for nurse practitioners or clinical specialists.

The relationstip of the two independent variables, type of role organization and degree of role deprivation, to specific behavioral variables in nursing practice should be examined, in order to further test the theory. For example, can it be demonstrated that role organization is associated 
with the number of continuing education credits nurses earn or their degree of involvement in patient advucacy activities? Does the quality of nursing practice vary in relation to type of role organization or degree of role deprivation? Are the variables useful in predicting selected bedaviors of nurses? Are they associated with the area of specialization nurses select or the type of setting in which they choose to practice?

As relationships between the variables of role organization type and degree of role deprivation and behavioral phenomena, attitudes, and beliefs are established, nen dimeñsious of the theoretical îramework may be hypothesized and further tested. Ultimately, the predictive power of these variables may ba established with a subsequent examination and modification of those factors which seem to determine types of role organization and promote role deprivation.

The theory of nursing role organization requires further study $0:$ variables that may be associated with the degrees of allegiance to the professional role, to the bureaucratic role, and with the degree of role deprivation experienced. The current study examined but two such variables. A multivariate analysis of the scores on the three scales of the role organization instrument would be useful in beginning to hypothesize and ultimately test specific cause and effect relationships. 
Since role deprivation bas been found to be associated with a number of factors important to the profession of nursing, such as job dissatisfaction, exodus from nursing practice, and degree of support for the advancement of education and practice of nursing, it seems imperative that factors operating in the work environment that contribute to role deprivation be examined in further research efforts. If such factors can be clearly identified, then nurses and service agency administrators may be able to work towards modifying or eliminating those factors. The result of such a process mas mell be a more satisfied and productive nurse employee who contributes significantly to the organization for a longer period of time.

The phenomenon of declining professional allegiance, as measured by the professional role conception scale scóre, among associate and baccalaureate prepared nurses over time in the job is worthy of further research. A replication of this aspect of the current study is recommended to determine if, in fact, this is pervasive among nurses. If it is found to be so, exploration of those variables operating in the work setting and contributing to a decline in allegiance to professional ideals is in order.

The role organization instrument, itself, may require further refinement, if it is to measure sensitively and consistently the constructs of professional and bureaucratic 
role conceptions and role deprivation. New items may need to be developed to better control internal sources of error and improve the instrument's reliability.

Lastly, a partial replication of the current study is recommended using multivariate analyses of nurses' degree of support for each facet of the resolution by examining a number of variables simultaneously, including type of role organization and educational preparation. Such an analysis could be helpful in providing a more adequate explanation of the lack of consensus among nurses regarding two major issues of the resolution: the two levels of licensure and practice; and the baccalaureate requirements for professional practice.

Perbaps no other professional group remains so divided in its riews of what should constitute the educational and practice requirement of its profession. A fully adequate understanding of the influences on the development of the nursing role and its effect on nurses' views toward such professional issues as the 1985 Resolution awaits further research and theory development. 


\section{REFERENCES}

American Nurses' Association Convention '78. American Journal of Nursing, June $1978, \underline{78}$ (6), 1232 .

Anderson, B. E. Nursing education in communtty junior colleges. Philadelphia: J. B. Lippincott, 1966 .

Ashley, J. Hospitals, paternalism and the role of the nurse. New York: Teachers College, Columbia University, 1977.

Ball, D. The cultural contradictions of capitalism. New York: Basic Books, 1976.

Bayer, A., \& Huston, A. C. The quality promise of nursing education policy. Educational Record, Fall 1973, 54 (4), 288-293.

Becker, H. S. Teacher in the authority system of the public school. Journal of Educational Sociology, November 1953, 27, 128-141.

Bensman, P. A. Have we lost sight of the $A D$ philosophy? Nursing Outlook, August $1977, \underline{25}$ (8), $511-513$.

Boyle, R. E. Articulation: From associate degree through masters. Nursing Outlook, October $1972,20(10), 670-672$.

Brim, 0. G., \& Wheeler, S. Socialization after childhood: Two essays. New York: John Wiley and Sons, Inc., 1966.

Brown, E. L. Nursing for the future. New York: Russe 11 Sage Foundation, 1948 .

Brown, J., Swift, Y., \& Oberman, M. Baccalaureate students' images of nursing: A replication. Nursing Research, January/February 1974 23. (1), 53-59.

Bullough, B., \& Bullough, V. A career ladder in nursing: Problems and prospects. American Journal of Nursing, October 1971, 71 (10), 1938-1943. 
Bullough, B., \& Sparks, C. Baccalaureate $\nabla$ s associate degree nurse: The care-cure dichotomy. Nursing Dutlook, November 1975,23 (1), 688-692.

Cleland, V. A human resource model for nursing. In Entry into nursing practice, proceedings of the national conference. Kansas City, Mo.: American Nurses' Association, February $13-14,1978,39-46$.

Cômìs, A.. The prốessionai education ot teachers. Boston: Aliyn and Bacon, Inc., 1965 .

Compentencies of the associate degree nurse on entry into practice. New York: National League of Nursing, publication Number 23-1731, 1978 .

Corwin, R. G. Role conception and mobllity aspiration: A study in the formulation and transformation of bureaucratic, professional and humanitarian nurse identities (Doctoral dissertation, University of Minnesota, 1960). Dissertation Abstracts International, 1960,21 (5), 1280. (University Hicrofilms No. 60-3505).

Corwin, R. G. The professional employee: A study of conflicts in nursing roles. American Journal of Sociology, May 1961,66 (6), 604-615. (a)

Corwin, R. G. Role conceptions and career aspirations: A study of identity in nursing. Sociological Quarterly, April 1961, $2,691-696$. (b)

Corwin, R. G. The professional employee: A study of conflict in nursing roles. In J. K. Skipper \& R. C. Leonard (Eds.), Social interaction and patient care. Philadelphia: J.. B. Lippincott, 1965, 34 1-356.

Corwin, R. G., \& Taves, M. J. Some concomitants of bureaucratic and professional conceptions of the nurse role. Nursing Research, Fall 1962 , 11 (4), 223-227.

Corwin, R. G., Taves, M. J., \& Haas, J. E. Professional disillusionment. Nursing Research, Summer 1961, 10 (3), $\overline{141-144}$. 
Cotanch, P. H. Self-actualization and professional socialization of nursing students in the clinical laboratory experience. Journal of Nursing Education, October 1981, 20 (8), 4-14.

Davis, F., \& Olesen, V. L. Baccalaureate students' images of nursing. Nursing Research, January/ February 1964, $13(1), 8-15$.

DeChow, G. H. Preparing the technical nurse practitioners, Journal of Nursing Education, August $1970, \underline{9}(\overline{3}), 2-3$.

DeChow, G. H. Nursing Education: The associate degree program. RN, May $1971, \underline{34}$ (5), 40-43.

Downie, N. M., \& Heath, R. W. Basic statistical methods. New York: Harper and Row, Publishers, 1970.

Dyer, M. Diploma schools oppose the A.N.A. 1985 proposal. Hospital Progress, November $1979,60(11), 6-8 ; 12$.

Educational preparation for nurse practitioners and assistants to nurses: A position paper. New York: American Nurses Association, 1965.

Educational preparation for nursing - $19 \overline{9} 75$. Nursing Outlook, September 1976, 24 (9), 572 .

Educational preparation for nursing - 1978 . Nursing Outlook, September 1979, 27 (9), 608-614.

Educational preparation of nurses: A rising national concern. Journal of Nursing Care, December $1980,13(12), 8-12$.

Elkin, F., \& Handel, G. The child and society: The process of socialization. New York: Random House, 1972 .

Entry into nursing practice; proceedings of the national conference. Kansas City, Ho.: American Nurses' Association, February 13-14, 1978 . 
Estok, P. J. Socialization theors and entry into the practice oi nursing. Image, February $1977, \underline{9}(1), 8-14$.

Etzioni, A. The semi-professions and their orgainization. New York: Free Press, 1969.

Fabayo, A. D. Nursing and the community college movement. Nursing Forum, 1980, 19 (2), $181-191$.

Fields, R. R. (Ed.). The community college movement. San Francisco: McGraw-Hill Book Company, 1962 .

Foss, M., \& Whipple, L. Open door education - Bringing the street corner to the college. Community and Junior College Journal, March 1 $\overline{973,43}(6)$, 18-19.

Getzels, J., \& Guba, E. G. Role, role conflict, and effectiveness: An empirical study. American Soclological Review, April 1954, 19 (2), 164-175.

Ginsberg, E., (Chairman, Committee on the Function of Nursing). A program for the nursing profession. New York: MacMillan Company, 1948.

Goldmark, J. Nursing and nursing education in the United States. New York: Mackillan, 1923.

Goss, M. E. Influence and authority among physicians in an out-patient clinic. American Sociological Review, February $1961, \underline{26}$ (1), 39-50.

Haase, P. T. Political crisis in associate degree nursing education: Implications for the college administrator. New York: National League of Nursing, Publication Number 23-1733, 1978 .

Eaberstein, R. W., \& Christ, E. A. Professionalizer, traditionalizer, and utilizer. Columbus, Mo.: University of Missouri, 1955.

Harnetiaua, M. SNAS report on entry into practice. AORN Journal, January 1979, 29 (1), 35-42.

Hasenfeld, Y., \& English, R. A. (Eds.). Human service organizations. Ann Arbor, Mich.: 
University of Michigan Press, 1974.

Heidgerkin, L. E. Tork values and career preferences of nurses for teaching and clinical nursing practice. Nursing Research, May/June 1970, 19 (3), $219-229$.

Hogstel, M. O. Associate degree and baccalaureate graduates: Do they function differently? American Journal of Nursing, October 1977 , 77 (10), 1598-1600.

Huck, S. W. , Cormier, W. H:, \& Pounds, W. G. Reading statistics and research. San Francisco: Harper and Row, Publishers, 1974.

Hughes, E. C. The making of a physician: General statement of ideas and problems. Human Organizations, Winter 1956, 14 (4), 21-25.

Hull, C. H., \& Nie, N. H. SpSS update. San Francisco: McGraw-Hill Book Company, 1979.

Ingles, T. Debate: Ladder concept in nursing education. Nursing Outlook, November $1971,19(11), 726-730$.

Katz, F. E. Nursing. In A. Etzioni (Ed.), The semi-professions and their organization.



Katzel1, M. E. Upward mobility in nursing. Nursing Outlook, September 1970, 18 (9), 36-39.

Kerlinger, F. N. Foundations of behavioral research (2nded.). San Francisco: Holt, Rinehart, and Winston, Inc., 1973.

Kinsinger, R. E. Partnership for junior college programs. American Journal of Nursing, September 1964, 64 (9), 104-106.

Klecka, W. R., Nie, N. H., \& Hull, C.H. Statistical package for the social sciences primer. San Francisco: McGrawHill Book Company, 1975.

Koffman, R., \& Andruskiw, C. From diploma or associate degree to bachelor's degree. 
American Journal of Nursing, November $1971, \underline{71}(11)$.

Kohke, if. F. Do nursing educators practice phat is preached? American Journal of Nursing, September 1973, 73 (9), 1571-1575.

Kramer, M. Nurse role deprivation - A symptom of needed change. Social Science and Medicine, December 1968, 2 (4), 461-474. (a)

Kramer, M. Role models, role conceptions, and role deprivation. Nursing Research, March/April 1968, 17 (2), 115-120. (b).

Eramer, M. Role conceptions of baccalaureate nurses and success in hospital nursing. Nursing Research, September/October 1970,19 (5), 428-439.

Kramer, M. Professiona1-bureauratic conflict and integrative role behavior. In.M. V. Batey (Ed.), Communicating nursing research - Is the gap being bridged? Boulder, Colo.: Western Interstate Commission for Higher Education, July 1971, 56-71.

Kramer, M., McDonnel, C., \& Reed, J.L. Selfactualization and role adaptation of baccalaureâte degree nurses. Nursing Research, March/April 1972, 21 (2), $111-123$.

Lee, A. A. Mandatory BSN: Something has to be done. RN, April 1979, 42 (4), 64-76. (a)

Lee, A. A. Seven out of ten nurses oppose the professional/technical split. RN, January 1979, 42 (1), 83-93. (b)

Lee, A. A. There has to be a better way. RN, February 1979, 42 (2), 39-46. (c)

Lee, A. A. Why feelings run high on the professional/technical split. RN, March 1979, $\underline{42}$ (3), 52-58

MacPhail, J. Nursing in the changing health care system: Direction for future roles. In 
Entry into nursing practice, proceedings of the national conference. Kansas City, Mo.: American Nurses' Association, February 13-14, 1978, 28-38.

MCClure, M. L. New York State's 1985 proposal. AaORĩ Journal, January $1979, \underline{29}$ (1), 48-53.

McClure: M. T., Entry into professional practice: The New York proposal. Jourral of Nursing Administration, June $1976,6(5), 12-17$.

McGlothlin, W. The professional schools. New York: Center for Applied Research in Education, 1964.

MCGriff, E. P. If not the 1985 resolution then what? Nursing Outlook, June $1980, \underline{28}(6), 365$.

McManus, R. I. The effect of experience on nursing achievement. New York: Bureau of Publications, Teachers College, Columbia University, 1949.

Meyer, L. Educational requirements raise controversey for health personnel. Hospitals, J.A.H.A., April 1, 1977, 51, 119-125.

Miller, G. A. Professionals in bureaucracy: Alienation among industrial scientists and engineers. American Sociological Review, October 1967, 32 (5), 755-768.

Minehan, P. I. Nurses' role conception. Nursing Research, September/October $1977, \underline{26}$ (5), 374-379.

Montag, M. L. Technical education in nursing? American Journal of Nursing, May $1963, \underline{63}$ (5), 100-103.

Montag, M. L. Reflections on the past 20 years and a look into the future. New York: National League of Nursing, Publication Number 23-1411, 1970 .

Montag, M. L. Evaluations of graduates of associate degree nursing programs. New York: Columbia University, Teachers College Press, 1972 . 
Myers, J. L. Fundamentals of experiemental design (2nd ed.). Boston: Allyn and Brown, 1972 .

Nie, iv. B., Huil, C. H., Jenkins, J. G., Steinbrenner, K., \& Bent, D. H. Statistical package for the social sciences (2nd ed.). San Francisco: MCGraw-Hill Book Company, 1975.

Nunnally, J. C. Psychometric theory (2nd ed.). San Francisco: McGrap-Hill Book Company, 1978.

Oregon State Board of Nursing annual statistical report, Fiscal year July 1,1977 - June 30,1378 . Portland, Or.: State Health Division.

Petrone, F. R. The case of the missing ladder. Jo urnal of Continuizg Education in Nursin̈g, $1978,9(4), 8-15$.

Proceedings of the forty-second convention of the American Nurses' Association. New York: American Nurses' Association, 1960.

Rosenberg, M., Suchman, A., \& Goldsen, R. K. Occupations and values. Glencoe, Ill.: Free press, 1957.

Rotkovich, R. The associate degree nurse: A nursing service perspective. Nursing Outlook, April 1976, 24 (4), 234-236.

Sarbin, T. R. Role theory. In G. Lindzey (Ed.), Handbook of social psychology (Vol. I). Cambridge, Mass.: Addison-Wesley Publishing Company, 1954, 223-258.

Scott, J. M. Federal support for nursing education to improve quality of practice. public Health Report, January/February 1 $\overline{979, \underline{94}}$ (1), 34.

Sheaban, D. the game of the name: Nurse professional and nurse technician. Nursing Outlook, July 1972,20 (7), 440-444.

Siegal, J. professional socialization in two baccalaureate programs. Nursing Research, September/October 1968, $17(5), 403-407$.

Singleton, E. Toward a realistic strategy for 1985 . $\underline{\mathrm{RN}}$, May 1979, 42 (5), 95-100. 
Special poll. RN, June 1978, 41 (6).

Summary proceedings of the fifty-first convention of the American Nurses ${ }^{\prime}$ Association. New York: American Nurses' Association, 1978 .

Taves, M. J., Corwin, R. G., \& Haas, J. Role conception and vocational success and satisfaction. Columbus, Ohio: Bureau of Business Research, College of Commerce and Administration, Ohio State University, 1963.

Tetreault, A. I. Selected factors associated with professional attitudes of baccalaureate nursing students. Nursing Research, January/February $1980,25(1), 49-53$.

The 1985 Proposal for entry into nursing practice - How should the ACNM respond? Journal of Nurse Midwifery, January/February 1980, 25 (I), $1-2$.

Two New York nurses debate the NYSNA 1985 proposal. American Journal of Nursing, June 1976,76 (6), 930-935.

Waters, V. Distinguishing characterists of associate degree education for nursing. New York: National League of Nursing, Publication Number 23-1722, 1978 .

Weisburd, M. R. Why organizational development hasn't worked (so far) in medical centers. Health Care Management Review, Spring 1976, 1 (2), 17-28.

Tood, L. Proposal: A career ladder for nursing. American Journal of Nursing, May 1973, 63 (5), 832-835.

Wooley, A. S. From RN to BSN: Faculty perceptions. Nursing Outlook, February 1978, 26 (2), 103-108. 


\section{Reference Notes}

1. Teaff, J., Assistant Executive Director, Oregon Nurses' Association. Personal communication. November 17,1981 .

2. Marshall, J. C. \& Hales, L. W. Research design and statistics for educators. Unpublished manuscript. St. Louis, Missouri, 1980.

3. Walters, M. B. Personal communication. July 29, 1982 .

4. Oregon State Board of Nursing. Personal communication. July 2,1981 .

5. Oregon Nurses' Association. Personal communication. July 2, 1981 . 
APPENDICES 
APPENDIX A

INVITATIONAL AND FOLLOW-UP LETTERS 
March 29, 1982

274 Sandy Drive

Salem, Oregon 97303

Both the American Nurses' Association and the Oregon Nurses' Association House of Delegates have proposed changes in nursing practice and licensure by 1985. If enacted into law, these changes would affect nurses throughout Oregon. However, it is not known what nurses like yourself think about these proposed changes. Further, to what extent nurses differ in their views of nursing practice and nursing education is not known.

You are one of a small number of nurses being asked to give your views on these matters. Your name was drawn from a random sample of nurses in the entire state. In order that the results will truly represent the thinking of Oregon nurses, it is important that each questionnaire be completed and returned.

You may be assured of complete confidentiality. The questionnaire has an identification number for mailing purposes only. This is so that I may check your name off of the mailing list when your questionnaire is returned. Your name will never be placed on the questionnaire, and no individual will be identified in this studg:

The questionnaire is divided into three sections. Part I asks your views of the American Nurses' Association's "1985 Resolution" on the two levels of nurstng practice, professional and technical, as well as your views on several issues related to this proposal. Part II asks your views of what you believe to be the current state of nursing practice in specific nursing situations, as well as what you believe should be the practice of nursing. Part III asks for certain demographic information. The questionnaire takes approximately 20 minutes to complete.

The results of this study will be made available to the staff of the Oregon Nurses' Association and interested nurses. You may receive a summary of results by writing "copy of results requested" on the back of the stamped, return envelope, and printing your name and address below it. Please do not put this information on the questionnaire itself.

Please complete and return the questionnaire by Apri. 7 , $\underline{1982}$.

I would be most happy to answer any questions you may have. 
Please write or call. The telephone number is (503) 682-1266.

Your assistance in better understanding the views of Oregon nurses toward important professional issues is greatly appreciated. Thank you for your cooperation in this study.

Sincerely,

Pauia G. Morton, R.N, M.N.

Doctoral Candidate

Portland State University. 
April 17, 1982

274 Sandy Drive

Salem, Oregon 97303

Last week a questionnaire seeking your opinion about nursing practice was mailed to you. Your name was drawn in a random sample of nurses in Oregon. I have not received your completed questionnaire.

If you have already completed and returned it to me, please accept my sincere thanks. If not, please do so today. Because it has been sent to only a small, but representative, sample of nurses, it is extrememly important that yours also be included in the study if the results are to accurately represent the views of Oregon nurses.

If gou did not receive the questionnaire, or it got misplaced, please call me today after 5 P.M. collect (503-682-i266) and I will get another one in the mail to you.

Thank you for your cooperation in this study.

Sincerely,

Paula G. Morton, R.N., M.N.

Doctoral Candidate

Portland State University 
Apri1 17, 1982

141

274 Sandy Drive

Salem, Oregon 97303

Several weeks ago a questionnaire was mailed to you. I have not received your completed questionnaire. In case it was misplaced, I am mailing you another with an explanation of the study below:

Both the American Nurses' Association and the Oregon Nurses' Association House of Delegates have proposed changes in nursing practice and licensure by 1985. If enacted into law, these changes would affect nurses throughout Oregon. However, it is not known that nurses like yourself think about these proposed changes. Further, to what extent nurses differ in their views of nursing practice and nursing education is not known.

You are one of a small number of nurses being asked to give your views on these matters. Your name was drawn from a random sample of nurses in the entire state. In order that the results will truly represent the thinking of Oregon nurses, it is important that each questionnaire be completed and returned.

You may be assured of complete confidentiality. The questionnaire has an identification number for mailing purposes only. This is so that I may check your name off of the mailing list when your questionnaire is returned. Your name will never be placed on the questionnaire, and no individual will be identified in this study.

The questionnaire is divided into three sections. Part I asks your views of the American Nurses' Association's "1985 Resolution" on the two levels of nursing practice, professional and technical, as well as your views on several issues related to this proposal. Part II asks your views of what you believe to be the current state of nursing practice in specific nursing situations, as well as what you believe should be the practice of nursing. Part III asks for certain demographic information. The questionnaire takes approximately 20 minutes to complete.

The results of this study will be made available to the staff of the Oregon Nurses' Association and interested nurses. You may receive a summary of results by writing "copy of results requested" on the back of the stamped, return envelope, and printing your name and address below i.t. Please do not put this information on the questionnaire itself.

Please complete and return the questionnaire by April 26; $\underline{1982}$. 
I would be most happy to answer any questions you may have. Please write or call. The telephone number is (503) 682-1266.

Your assistance in better understanding the views of oregon nurses toward important professional issues is greatly appreciated. Thank you for your cooperation in this study.

Sincerely,

Paula G. Morton, R.N., M.N. Doctoral Candidate Portland State University 


\section{APPENDIX B}

INSTRUMENTATION 
The 1985 Resolution

The 1985 Resolution on Entry into Professional practice was approved by the American Nurses' Association in 1978. It has subsequently been adopted by Oregon Nurses' Association House of Delegates. The resolution is presented below:

"Whereas, The existence of multiple kinds of basic nursing education programs leading to licensure as a registered professional aurse creates immeasureable public and professional confusion, and

Whereas, It has also long been recognized that baccalaureate preparation is basic to professional nursing practice, Therefore Be It Resolved, That the...Association develop a plan establishing by 1985 the baccalaureate degree in nursing as a requirement for licensure as a registered professional nurse, and be it further Resolved, That this effort provide through grandfather clauses and/or other appropriate means, full protection of all practice privileges, titles and status of all individuals currently licensed or preparing for licensure as a registered professional nurse."

Insruction:

This section consists of four items related to the Autericia Nurses' Association's proposal for two levels of nursing practice, one technical and one professional. You are asked to indicate your degree of agreement or disagreement with each of the four statements by circling one of the alternative responses. There are no "wrong" answers.

SA indicates you strongly agree with the statement

A Indicates you agree with the statement

D indicates you disagree ith the statement

SD Indicates you strongly disagree with the statement

1. Nursing should be divided into "Registered Professional" and "Registered Technical" nurses mith two distinct types of educational preparation, instead of the present system of B.S., Diploma, A.D. for R.N.S and Practical/Vocational for L.P.N.S/L.V.N.S.

SA $\quad A \quad D \quad S D$ 
CONFIDENTIAL

2. When the proposal is implemented, the Bachelor's Degree should be required for liceasure as a "Registered professional Nurse".

SA A D SD

3. Legislation implementing the proposal should not include a "grandfather clause" granting Registered Professional status to all current R.N.s and Registered Technical status to all current L.P.N.S/L.V.N.S.

SA A D $\quad$ SD

4. When the proposal is implemented, a "Registered Technical Nurse" should be allowed to enter ang "Registered professional Nurse" educational program with full credit for previous nursing education.

SA $\quad$ A $\quad$ D $\quad S D$ 
PLEASE NOTE:

Copyrighted materials in this document have not been filmed at the request of

the author. They are available for consultation, however, in the author's university library.

These consist of pages:

Role Organization-Ronald Corwin (pages 146-150)

\section{University \\ Mic rofilms International}

300 N Zeeb Rd., Ann Arbor, Ml 48106 (313) 761.4700 
$\underline{\text { Part III }}$

GENERAI. INFORMATION

Instruetions:

This section consists of demographic information. Please indicate the correct information by circling the appropriate alternative for each of the items. All responses kept confidential.

19. Tour sex. (Circle number of your ansper)

$$
\begin{aligned}
& 1 \text { FEMALE } \\
& 2 \text { MALE }
\end{aligned}
$$

20. Your age. (Circle number)

1 ONDER 25

$2 \quad 25$ TO 34

$3 \quad 35$ TO 44

4.45 AND OVER

21. Your level of basic nursing education. (Circle number)
1 ASSOCIATE DEGREE
2 DIPLOMA
3 BACCALAUREATE DEGREE

22. Highest level of nursing education attained other than basic preparation. (Circle number)

$\begin{array}{ll}1 & \text { BACCALAUREATE (NURSING) } \\ 2 & \text { MASTER'S (NORSING) } \\ 3 & \text { DOCTORATE (NURSING) } \\ 4 & \text { NONE OTHER THAN BASIC NORSING } \\ & \text { PREPARATION }\end{array}$

23. Highest degree beld outside of aursing. (Circle number)

$\begin{array}{ll}1 & \text { ASSOCIATE DEGREE } \\ 2 & \text { BACCALADREATE DEGREE } \\ 3 & \text { MASTER'S DEGREE } \\ 4 & \text { DOCTORATE } \\ 5 & \text { NONE }\end{array}$


24. Your number of years of nursing experience. (Circle n umber)

$$
\begin{array}{llll}
1 & 0 & \text { TO } 9 & \text { YEARS } \\
2 & 10 & \text { TO } 19 & \text { YEARS } \\
3 & 20 & \text { YEARS AND OVER }
\end{array}
$$

25. 'Hember of American Nurses' Association. (Circle number )

$$
\begin{array}{ll}
1 & \text { YES } \\
2 & \text { NO }
\end{array}
$$

26. Type of institution. in which you are curreaty employed. (Circle number)

$\begin{array}{ll}1 & \text { NOT CORRENTLY EMPLOYED } \\ 2 & \text { HOSPITAL } \\ 3 & \text { DOCTOR'S OFFICE } \\ 4 & \text { COMMONITY HEALTH AGENCY } \\ 5 & \text { THO YEAR COLLEGE } \\ 6 & \text { DIPLOMA SCHOOL } \\ 7 & \text { FOUR YEAR COLLEGE } \\ 8 & \text { NURSING HOME } \\ 9 & \text { OTHER TYPE OF FACILITY } \\ \text { (PleaSe SPECIPY: }\end{array}$

Your contribution to this effort is very greatly appreciated. If you would like a summary of results, please prite "copy of results requested" on the back of the return envelope, and print your name and address below it (NOT or this questionnaire). I pill see that you get ic. 